\title{
A Model for the Assessment of Different Net-Metering Policies
}

\author{
Georgios C. Christoforidis ${ }^{1, *}$, Ioannis P. Panapakidis ${ }^{1}$, Theofilos A. Papadopoulos ${ }^{2}$, \\ Grigoris K. Papagiannis ${ }^{3}$, Ioannis Koumparou ${ }^{4}$, Maria Hadjipanayi ${ }^{4}$ and George E. Georghiou ${ }^{4}$ \\ 1 Department of Electrical Engineering, Western Macedonia University of Applied Sciences, 50100 Kozani, \\ Greece; ipanap@ee.auth.gr \\ 2 Department of Electrical \& Computer Engineering, Democritus University of Thrace, 67100 Xanthi, Greece; \\ thpapad@ee.duth.gr \\ 3 School of Electrical and Computer Engineering, Aristotle University of Thessaloniki, 54124 Thessaloniki, \\ Greece; grigoris@eng.auth.gr \\ 4 FOSS Research Centre for Sustainable Energy, PV Technology, Department of Electrical and Computer \\ Engineering, University of Cyprus, 1678 Nicosia, Cyprus; ikoump01@ucy.ac.cy (I.K.); \\ hadjipanayi.maria@ucy.ac.cy (M.H.); geg@ucy.ac.cy (G.E.G.) \\ * Correspondence: gchristo@teiwm.gr; Tel.: +30-24610-68141
}

Academic Editor: Rodolfo Araneo

Received: 14 January 2016; Accepted: 21 March 2016; Published: 1 April 2016

\begin{abstract}
The photovoltaic market has recently experienced an enormous expansion, mainly due to the generous Feed-in-Tariffs (FiTs) adopted by many countries. However, in the recent years FiTs have been considerably reduced or even disappeared as their role in the PV deployment has ended. One of the alternatives is the Net-Metering (NEM) policy, which has attracted the interest of stakeholders as it provides a basis for the efficient collaboration between generation and the consumption profiles of the consumer. Currently, there is a lack of a universal policy harmonizing the respective legislations of the E.U. member countries. This paper proposes a novel generalized methodology for the techno-economic assessment of different NEM policies in terms of profitability for the prosumer. The methodology is tested in a formulated case study based on the current NEM policy in Greece. The method proposed uses as inputs the averaged load profiles constructed from real measurements collected from 31 consumers in the Thessaloniki area and evaluated PV production. The current NEM policy and four alternatives are examined, using as additional input the average system marginal prices of the year 2013. The results show that the proposed methodology is capable of evaluating a wide variety of NEM policies and can lead to suggestions for policy adaptation in order to establish a win-win contract between all interested stakeholders.
\end{abstract}

Keywords: energy policy; net-metering (NEM); photovoltaics; techno-economic analysis

\section{Introduction}

Photovoltaic (PV) technologies are an expanding market segment in modern power markets. The utilization of PVs in distributed generation offers a set of changes and challenges that have been analyzed extensively by numerous studies [1]. PV installations have increased considerably in recent years in many countries. One of the key factors that have served as the basis for the continuous increase of installations was the introduction of the Feed-in-Tariffs (FiTs), a favorable policy mechanism in many EU countries. In a global context, PV installations have increased from almost $1 \mathrm{GWp}$ in 1998 to more than $177 \mathrm{GWp}$ by the end of 2014, with $38.7 \mathrm{GWp}$ of PV implementations taking place only in 2014 [2]; among them, the installations in Europe account for $87 \mathrm{GWp}$, approximately [3]. By the end of 2014, Germany had already installed $38.3 \mathrm{GWp}$ of PV power. On the contrary, in the high solar potential Mediterranean region countries, Italy had installed 18.45 GWp followed by France with 5.6 GWp, 
Spain with $4.7 \mathrm{GWp}$ and Greece with $2.6 \mathrm{GWp}$. In all these countries the FiT policy mechanism was employed. In other Mediterranean countries where the FiT policy was employed later or not employed at all, PV growth was limited. By the end of 2014, the installed PV capacity in Portugal was 419 MWp, in Slovenia $256 \mathrm{MWp}$ and in Cyprus 64.8 MWp [3]. However, the FiT policy was not designed to last forever. Thus, all fixed tariffs started to decline or even were abolished in certain countries. This led to a decrease in PV installation across Europe. In fact, the newly installed capacity in Europe declined from $16.70 \mathrm{GWp}$ in 2012 to $10.1 \mathrm{GWp}$ in 2013 and just $6.88 \mathrm{GWp}$ in 2014 [4]. This led to a European Union market share drop from $73.6 \%$ in 2012 to $26.5 \%$ in 2013 and just $17.7 \%$ in 2014 .

Recently, Net-Metering (NEM) has attracted the interest from energy stakeholders, such as the regulatory authorities, utilities, and decision makers. NEM offers an alternative option for positive investment opportunities from small scale PV generation, especially in the residential sector $[5,6]$. Under NEM, the prosumer (a customer who at the same time produces and consumes energy) offsets the energy consumed within its premises with energy produced from a local (rooftop) PV system. It should be noted that NEM allows the energy consumption and production to happen at different times. This fact distinguishes NEM policies from others such as self-consumption or tax reductions for self-consumed electricity. The charge is based on the "net amount" between the consumed and produced energy in different netting periods depending on the contract. In the case of negative netting, i.e., the production is lower than the consumption, the prosumer can be charged either only for the "net" energy consumed or including additional charges as a compensation for using the transmission and distribution grid and other grid services. If the produced energy is higher (the case of a positive net amount), a NEM policy may foresee the compensation of the excess energy at various prices, or not.

Regarding the EU countries, the introduction of NEM policies are relatively limited, but due to the interest of many parties, it is expected to play an active role in the coming years [7]. The currently limited implementation of NEM policies is due to barriers such as the installation capacity limits, settlement period (i.e., the netting balance calculation period), compensation or not of the excess electricity (i.e., in cases of positive netting), the price of the compensated energy and others. These factors lead to the adaptation of country specific NEM policies, implying a lack of a general EU policy that will harmonize the respective laws in every member country $[8,9]$.

NEM variations are plentiful and, therefore, policies in different countries or regions can vary significantly. The basic questions that arise regarding a NEM policy are: (a) whether a full or partial netting approach should be regarded; (b) whether the excess energy should be compensated and at what price; and (c) what happens in cases of extra charges posed by the utilities to account for the grid services. From the prosumer's perspective, the focus of interest is the optimal PV system size in accordance with the consumption profile, in terms of making a PV investment attractive under a specific NEM policy. Some initial studies in the USA [10-14] and just recently in the rest of the world [15-19], have discussed some of the above issues and investigated the influence of different techno-economic parameters on the bill savings of net-metered PV customers. However, a generalized methodology capable of being applied to many alternative NEM policies has not been proposed yet, according to the authors' knowledge.

In this context, the scope of this study is the development and testing of a model and a concise methodology for the evaluation of the attractiveness of various NEM policies to prospective PV prosumers. By using this methodology a wide variety of scenarios can be examined, which may help policy makers in fine-tuning policy alternatives and keep at the same time adequate profitability for the prosumer. The model characteristics follow the guidelines of the research held in the "Promotion of PV energy through net metering optimization" (PV-NET) project, co-funded by the European Territorial cooperation 2007-2013 programme MED and by national funds, which resulted in the development of a sophisticated optimization tool [20]. Overall, the objective is to pave the way for more efficient Renewable Energy Resources (RES) exploitation in the Mediterranean through a more cost-effective RES incorporation into the energy mix. Thus, the objectives of the PV-NET project are highly relevant 
to EU policies and targets. The results of the PV-NET can form a basis for a cost-effective and energy efficient implementation of RES in the Mediterranean and the EU as a whole.

The proposed methodology is tested in a case study based on the experience gained from the newly established NEM policy in Greece. Since there is a lack of research in investigating NEM alternatives, this paper examines a series of NEM options for the Greek system. A scenario-based approach that simulates a series of different options is used to test the methodology. These scenarios consider both full and partial netting mechanisms and involve hourly netting options. Moreover, the proposed model allows examining different PV installation characteristics, consumption patterns, and financial parameters. The outputs of the model are the billing savings of the prosumer expressed in yearly cash-flows and relevant investment appraisal indicators. This makes the model a prosumer oriented tool that estimates the economic benefits given a NEM mechanism.

The rest of the paper is structured as follows: in Section 2 the current situation of the PV market in Greece is outlined along with a description of the recently adopted NEM policy. Section 3 presents the proposed methodology for assessing NEM policies, which consists of three stages. In Section 4 the case study used for the testing of the methodology is defined, along with the examined policy scenarios. Section 5 presents the results from the implementation of the methodology on the case study and finally conclusions and useful recommendations are included in Section 6.

\section{PV and Net-Metering Status in Greece}

\subsection{Status of PV Installations in Greece}

The PV market in Greece experienced a rapid increase in the previous years. This was mainly due to the generous FiTs, the support policy mechanism employed in a majority of countries worldwide. The FiTs along with the high solar energy potential of Greece and the considerable decrease in PV system prices attracted many PV investments in Greece. It was no surprise therefore that the number of PV installations rose steeply, leading to the development of a dynamic professional sector. It is notable that since 2013 the total installed PV capacity has surpassed the installed capacity of wind power, which is rarely found. Figure 1 illustrates the cumulative PV capacity and the monthly PV energy production in Greece, between 2012 and 2015.

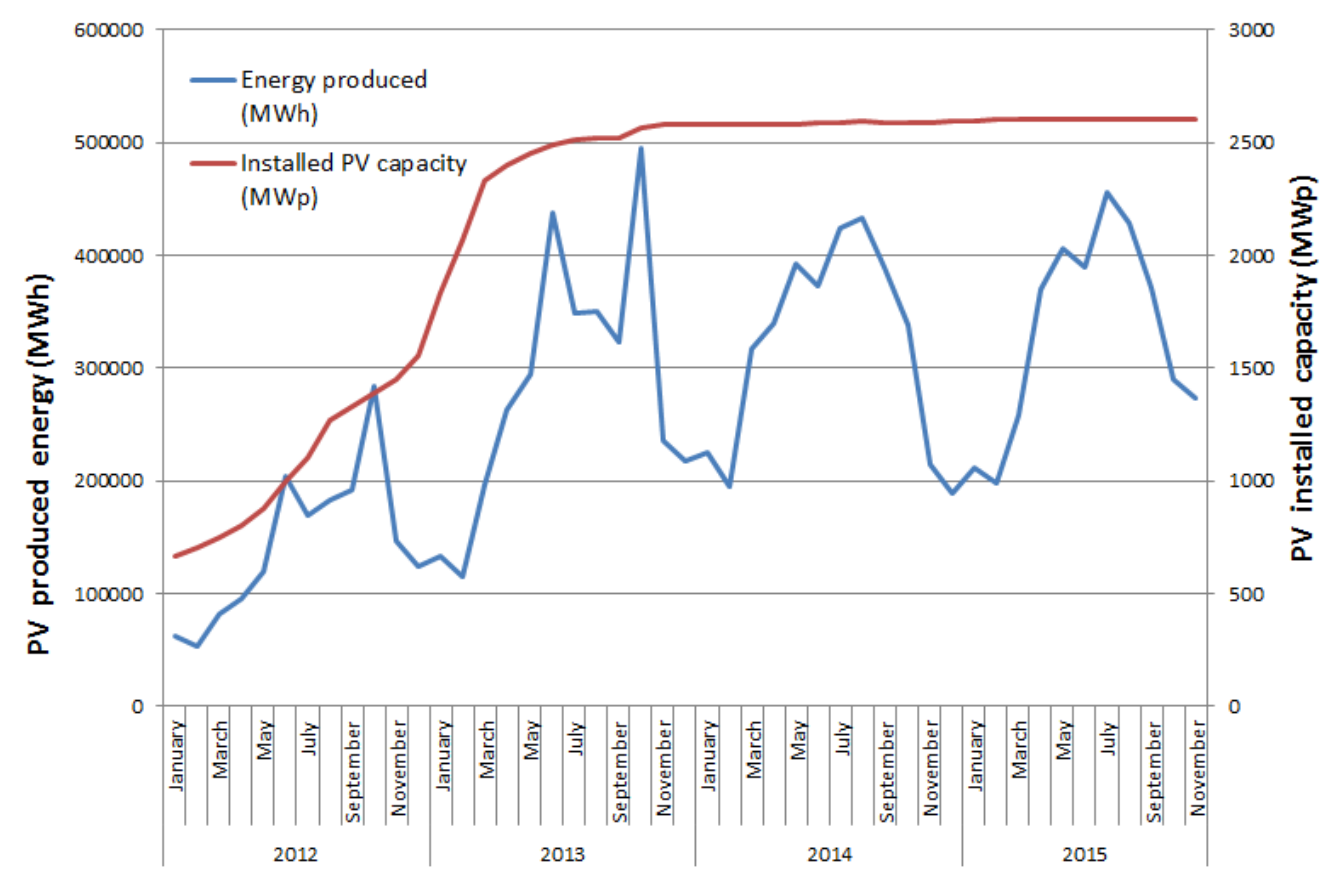

Figure 1. Evolution of installed PV power and energy production in Greece. 
Inspecting Figure 1, it is clear that neither the rapid increase in PV installations experienced between January 2012 and March 2013 (where PV installed capacity almost tripled) nor the remarkably steady curve over the last three years contribute to a sustainable market sector. Indeed, this steep increase in installed PV capacity exceeded the provisions made by the national authorities, which had set the targets of reaching PV capacity of $1.5 \mathrm{GWp}$ by 2014 and $2.2 \mathrm{GWp}$ by 2020 . These numbers were already reached by February 2013, but the overall situation resulted in a series of unpleasant distortions for all stakeholders involved. This was mainly due to the fact that the financing mechanism for the FiTs was not properly designed and, more importantly, it was not adaptive to PV system price drops, leading to PV investments with very high returns. In fact, according to the monthly report of the RES Special Account (RESSA) issued by the market operator, the weighted average price at the end of 2012 for PV produced energy was $420 € / \mathrm{kWh}$ for free-standing installations and $550 € / \mathrm{MWh}$ for roof-top ones. The main outcome was the establishment of a huge deficit in the RESSA, since one of its major credit components (the RES tax) was not increased accordingly due to a political decision. This situation subsequently led to an initial indirect FiT reduction (added taxation) and then to an official reduction of the existing contracts (termed as "new deal"). The PV market actors in Greece have warned about the urgent need for market revitalization in order to preserve the market.

\subsection{Status of PV Net-Metering (NEM) in Greece}

Considering the situation of the PV market presented in Section 2.1, the notion of NEM was introduced as a means to revive the market and at the same time to avoid creating further deficits in RESSA, which would have led to an increase of the RES tax for all consumers. NEM was first introduced in November 2013 by Law 4203 [21]. That law remained practically inactive until December 2014 when the required Ministerial decision concerning the exact provisions for NEM was published [22]. This ended a long discussion between interested parties that lasted for more than one year and after a public consultation on a certain proposal, which was examined in a recent article [23]. The main provisions of the policy are the following:

- Installation capacity limits: Premises with a capacity contract of up to $40 \mathrm{kVA}$ can implement a NEM PV system up to $20 \mathrm{kWp}$. For premises with higher capacity contracts, the limit is set to $50 \%$ of the capacity contract with a maximum PV capacity of $100 \mathrm{kWp}$.

- Billing period: The netting is calculated at the end of every billing period which is 4 months for the residential tariffs and 1 month for small industrial tariffs. In the case of a positive net amount (net $\left.=\mathrm{PV}_{\text {production }}-\mathrm{Grid}_{\text {consumption }}\right)$, the prosumer is not directly compensated but the excess energy is transferred to the next billing period in the form of Renewable Energy Credits (REC). This continues for all subsequent billing periods during the year (netting period).

- Regarding the competitive charges, the prosumer is charged based on the net amount within a billing period, adding the RECs transferred from the previous one. On the other hand, the prosumer is charged for the total amount of energy consumed (i.e., energy absorbed from the grid plus PV produced energy) for the "services of general interest" charge. The Transmission and Distribution (T \& D) charges and the RES tax are calculated based on the amount of imported energy from the grid. This was deemed necessary in order not to endanger the RESSA once more.

- The above imply that three charge categories exist related to the adopted NEM policy. A charge that is fully netted (the competitive charge), a charge category that depends on the imported energy from the grid (T \& D and RES charges) and a category that is non-netted (services of general interest charge).

\subsection{Levelized Cost of Electricity from PV Systems in Greece}

The Levelized Cost of Electricity (LCOE) in general is a benchmarking tool used to assess attractiveness and cost-effectiveness of different generation technologies. Concerning PV's, LCOE is used for comparison with traditional energy generation technologies. The LCOE is defined as the sum 
of the initial cost of the system and the Net Present Value (NPV) of all the costs over the lifetime of the investment (Operation and Maintenance Costs), divided by the energy generated from the system over its lifetime as shown in the following equation:

$$
L C O E=\frac{I+\sum_{t=1}^{n} \frac{C_{t}}{(1+r)^{t}}}{\sum_{t=1}^{n} \frac{E_{t}}{(1+r)^{t}}}
$$

where $I$ is the initial investment; $C_{t}$ is the operational \& maintenance $(\mathrm{O} \& \mathrm{M})$ expenditures in year $t ; R$ is the discount rate (DR); $N$ represents the investment period (in years) and $E_{t}$ is the energy yield in year $t$.

The result is the price per $\mathrm{kWh}, € / \mathrm{kWh}$, at which electricity generated from a PV system must be charged in order to break-even over the lifetime of the system. When the LCOE is lower than the retail electricity prices, then the PV technology is likely to be considered competitive with other generation technologies. This situation is identified with the term PV Grid Parity (PVGP).

Table 1 collects the results from the LCOE calculation using the above formula. The PV system initial investment varies between 1.2 and $2 € / \mathrm{Wp}$, the DR between $0 \%$ and $10 \%$, the $\mathrm{O} \& \mathrm{M}$ costs are set equal to $1.5 \%$ of the initial capital cost. The lifetime of the PV system is assumed to be either 20 years, as this is regarded as a benchmark time horizon for the techno-economic evaluation of common PV sites [4], or 25 years, as this is the maximum duration of the NEM contract in Greece. However, when a lifetime of 25 years is assumed, the replacement of the inverter should be considered as well. The inverter replacement cost after 20 years is roughly estimated at $20 \notin € / W_{n}$ as in [24]. The energy yield of the PV systems is set to vary between 1300 and $1800 \mathrm{kWh} / \mathrm{kWp}$. This was approximately the range of the real annual energy yield from PV plants in various locations in Greece, according to measurements presented in [25].

As expected, the choice of the DR heavily influences the LCOE calculation and, therefore, it should be chosen wisely. Also, when the lifetime is assumed at 25 years, the LCOE results in slightly lower values, however, the uncertainty of the inverter replacement cost after 20 years leads us to consider for the remaining of the text a lifetime period of 20 years.

\section{Proposed Methodology}

This section outlines the methodology used in this work, which is divided into three parts. It was devised with the intention to make it as general as possible so that it may also cover other NEM policies that this paper does not deal with. The goal of the methodology is to determine the annual profits for a prosumer under a certain NEM policy. Afterwards, a standard financial analysis is performed to evaluate the attractiveness of a NEM policy from a prosumer's point of view. This methodology was also used to develop the optimization tool described in [20].

\subsection{First Stage: Pre-Processing and Modeling}

The methodology begins with the pre-processing stage, where the required input data concerning both the prosumer's load and the PV generation are determined. A generalized methodology may skip this part and proceed to directly input measured or predicted data into the next stage, however, a pre-processing stage makes it easier to perform mass calculations and keeps calculation time limited.

\subsubsection{Electrical Load Modeling}

Generally, electrical load data can be obtained through actual measurements at various time steps. Alternatively, when measurements are not available, averaged load profiles may be used that correspond better to the prosumer's profile. For reasons related mainly to the availability of climatic data in various databases, the methodology uses monthly load profiles. 
Table 1. PV LCOE calculation for various annual energy yields and system cost in Greece.

\begin{tabular}{|c|c|c|c|c|c|c|c|c|c|c|c|c|c|}
\hline \multirow{4}{*}{ PV System Cost $\left(€ / W_{p}\right)$} & \multirow{4}{*}{ DR $(\%)$} & \multicolumn{12}{|c|}{ LCOE ( $₫ € / k W h)$} \\
\hline & & \multicolumn{12}{|c|}{ Annual Energy Yield (kWh/kWp) } \\
\hline & & \multicolumn{2}{|c|}{1300} & \multicolumn{2}{|c|}{1400} & \multicolumn{2}{|c|}{1500} & \multicolumn{2}{|c|}{1600} & \multicolumn{2}{|c|}{1700} & \multicolumn{2}{|c|}{1800} \\
\hline & & 20 Years & 25 Years & 20 Years & 25 Years & 20 Years & 25 Years & 20 Years & 25 Years & 20 Years & 25 Years & 20 Years & 25 Years \\
\hline \multirow{3}{*}{1.2} & 0 & 6.92 & 6.84 & 6.42 & 6.35 & 5.99 & 5.93 & 5.62 & 5.56 & 5.29 & 5.23 & 4.99 & 4.94 \\
\hline & 5 & 9.77 & 9.50 & 9.07 & 8.82 & 8.47 & 8.23 & 7.94 & 7.71 & 7.47 & 7.26 & 7.05 & 6.86 \\
\hline & 10 & 13.2 & 12.9 & 12.3 & 12.0 & 11.5 & 11.2 & 10.8 & 10.5 & 10.1 & 9.90 & 9.57 & 9.35 \\
\hline \multirow{3}{*}{1.4} & 0 & 8.07 & 7.87 & 7.49 & 7.31 & 6.99 & 6.82 & 6.56 & 6.39 & 6.17 & 6.02 & 5.83 & 5.68 \\
\hline & 5 & 11.4 & 11.0 & 10.6 & 10.2 & 9.88 & 9.54 & 9.26 & 8.94 & 8.72 & 8.41 & 8.23 & 7.95 \\
\hline & 10 & 15.5 & 15.1 & 14.3 & 13.4 & 13.4 & 13.1 & 12.6 & 12.2 & 11.8 & 11.5 & 11.2 & 10.9 \\
\hline \multirow{3}{*}{1.6} & 0 & 9.22 & 8.89 & 8.56 & 8.26 & 7.99 & 7.71 & 7.49 & 7.23 & 7.05 & 6.80 & 6.66 & 6.42 \\
\hline & 5 & 13.0 & 12.5 & 12.1 & 11.6 & 11.3 & 10.8 & 10.6 & 10.2 & 9.96 & 9.57 & 9.41 & 9.03 \\
\hline & 10 & 17.7 & 17.2 & 16.4 & 15.9 & 15.3 & 14.9 & 14.3 & 13.9 & 13.5 & 13.1 & 12.8 & 12.4 \\
\hline \multirow{3}{*}{1.8} & 0 & 10.4 & 9.92 & 9.63 & 9.21 & 8.99 & 8.60 & 8.43 & 8.06 & 7.93 & 7.59 & 7.49 & 7.16 \\
\hline & 5 & 14.6 & 14.0 & 13.6 & 13.0 & 12.7 & 12.2 & 11.9 & 11.4 & 11.2 & 10.7 & 10.6 & 10.1 \\
\hline & 10 & 19.9 & 19.3 & 18.4 & 17.9 & 17.2 & 16.7 & 16.1 & 15.7 & 15.2 & 14.8 & 14.3 & 13.9 \\
\hline \multirow{3}{*}{2} & 0 & 11.5 & 10.9 & 10.7 & 10.2 & 9.99 & 9.48 & 9.37 & 8.89 & 8.82 & 8.37 & 8.33 & 7.90 \\
\hline & 5 & 16.3 & 15.5 & 15.1 & 14.4 & 14.1 & 13.5 & 13.2 & 12.6 & 12.4 & 11.9 & 11.8 & 11.2 \\
\hline & 10 & 22.1 & 21.4 & 18.8 & 19.9 & 19.1 & 18.6 & 17.9 & 17.4 & 16.9 & 16.4 & 15.9 & 15.5 \\
\hline
\end{tabular}


The load profiles are calculated from measured data covering a 12-month period following the pre-processing procedure of Figure 2a.

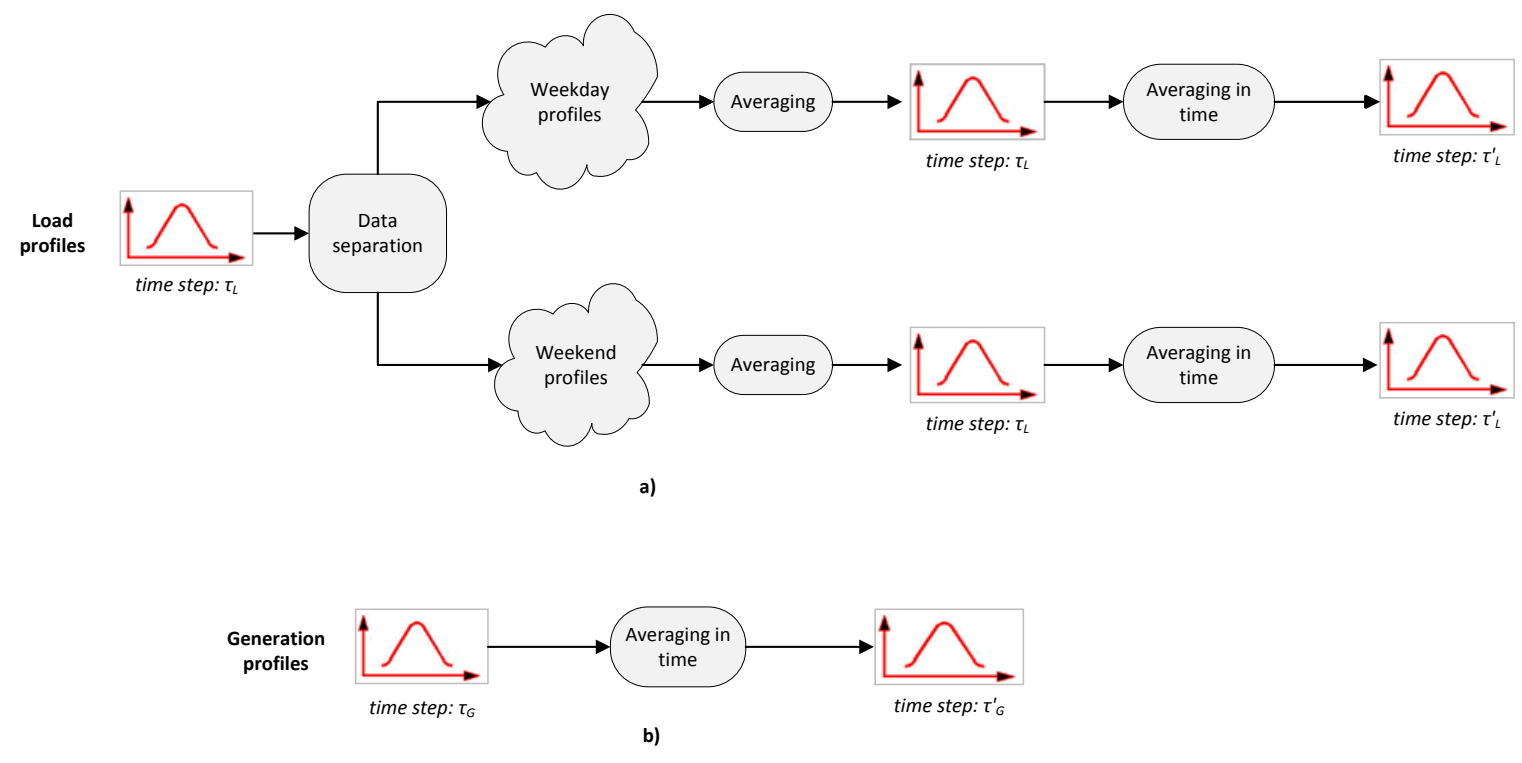

Figure 2. Flowchart of the pre-processing procedure for (a) load and (b) PV generation profiles.

First, the available data are separated into two distinct groups related to the customer demand during weekends/holidays and weekdays. Next, the consumption profile of the customer at a given month is evaluated by averaging the load data as separated in the previous stage. In total, twenty-four annual load curve patterns are constructed, two for each month of a year. Moreover, the gathered input data may be at different time step $\left(\tau_{L}\right)$ than the one used for the load profiles. The required load curves are adapted to the model's time step by averaging in time the data based on the model's time interval $\left(\tau_{L}^{\prime}\right)$.

\subsubsection{PV Generation Modeling}

Considering the PV generation, a similar procedure can be followed as shown in Figure $2 b$, if real data recorded from PV installations are used. Alternatively, PV generation data can be obtained from other sources, such as the Photovoltaic Geographical Information System (PVGIS) online platform of the EU Joint Research Centre. The PVGIS on-line tool provides the solar resource for the countries of Europe and Africa, along with relevant climatic data for a typical day of each month in 15-min. time steps [26]. The hourly PV energy production is calculated using Equation (1). There, the available solar irradiance on a fixed plane is denoted as, $H_{h}\left(\mathrm{~W} / \mathrm{m}^{2}\right)$, the installed capacity as $P(\mathrm{kWp})$ and the performance ratio as $P R$ :

$$
G_{h}=H_{h} \cdot P \cdot P R
$$

The performance ratio, $P R$, can be evaluated by employing Equation (2), where, $n_{1}, n_{2}$, and $n_{3}$ are the performance ratio of inverters, cables and electrical panel respectively, $\sigma_{P}$ is an optional coefficient related to air pollution and $\sigma_{T}$ is the air temperature coefficient.

$$
P R=\left(n_{1} \cdot n_{2} \cdot n_{3}\right) \times\left(\sigma_{T} \cdot \sigma_{P}\right)
$$

The air temperature coefficient, $\sigma_{T}$, is calculated using the empirical relationship of Equation (3).

$$
\sigma_{T}=1-\frac{T_{h}+10}{200}
$$


The data provided by the PVGIS service have a resolution of 15-min ( $\left.\tau_{G}=15-\mathrm{min}\right)$. Therefore, an averaging in time procedure must be utilized if the chosen interval $\tau^{\prime}{ }_{G}$ for the load profiles is different. For example, if an hourly interval is utilized, the hourly PV generation data are calculated by applying the averaging in time procedure, as shown in Figure $2 b$.

\subsection{Second Stage: Determination of Profits for a Prosumer under a NEM Policy}

The outputs of the pre-processing stage, i.e., the load and PV generation profiles related to the prosumer are used for the evaluation of the annual profits under a NEM policy. However, since various NEM policies exist, a generalized formulation is needed in order to model and assess possible policy variations.

\subsubsection{Energy Consumption and Production}

A NEM policy may use various elements related to the consumption and production of electrical energy within a time step. In order though to utilize some of the following elements in a real installation, a configuration using two meters is required. In case a new perspective installation is evaluated, the estimation of the self-consumption and the utilization rates may be necessary. These are defined with the aid of Figure 3 as follows:

- the self-consumption rate $\left(S C_{r}\right)$ is the ratio between the PV energy directly consumed on-site over the total PV energy production, that is: $S C_{r}=(c / c+b) \times 100$.

- the utilization rate $\left(U_{r}\right)$ is a measure of the percentage of PV energy used on-site compared with the total energy demand. This means: $U_{r}=(c / a+c) \times 100$.

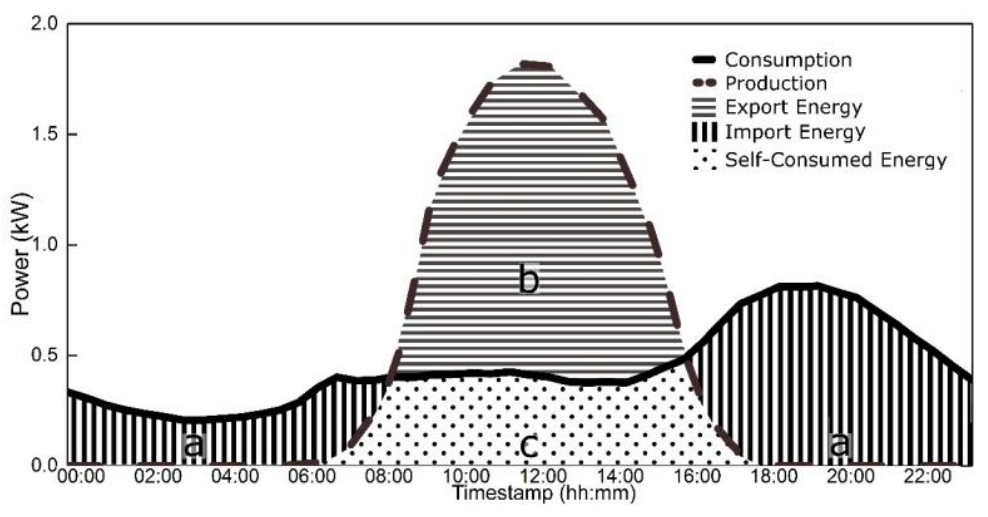

Figure 3. Sample PV production and consumption profiles of a certain installation at one time step.

In this context, the following elements are determined for every time step:

- Energy generation $E_{G \tau}(\mathrm{kWh})$ : the produced PV energy from the installed PV system within the time step $\tau$ used. It can be measured using a dedicated meter, or obtained from the pre-processing stage.

- $\quad$ Energy demand $E_{D \tau}(\mathrm{kWh})$ : the electrical energy absorbed from the grid during time step $\tau$.

- $\quad$ Energy feed $E_{F \tau}(\mathrm{kWh})$ : the electrical energy injected to the grid during time step $\tau$. The last two elements can be measured using one bi-directional meter, or obtained from the pre-processing stage and an estimation for the $S C_{r}$.

- Netted energy $E_{N \tau}(\mathrm{kWh})$ : the net electrical energy consumed during time step $\tau$, calculated by subtracting the injected energy from the absorbed energy i.e., $\left(E_{D \tau}-E_{F \tau}\right)$.

- Energy consumption $E_{C \tau}(\mathrm{kWh})$ : the real electrical energy consumed within the prosumer's premises during $\tau$. This can be obtained from the pre-processing stage or calculated with the formula $\left(E_{D \tau}+E_{G \tau}\right)-E_{F \tau}$. 


\subsubsection{Electricity Cost and Revenue}

An important parameter regarding a NEM policy is the cost that a customer has to pay for consuming electrical energy from the grid, i.e., the electricity retail tariff. Although each region/country may have different electricity cost categories and pricing, a breakdown of the retail electricity prices into four cost categories is generally common, enabling cross-country comparisons. These cost categories are the production cost, network cost, standing fees, taxes and VAT. However, from a NEM policy perspective, the important issue is how a prosumer is charged at each billing period. In that sense, a more appropriate breakdown of the electricity cost for a NEM prosumer is the following:

- Netted $\operatorname{cost} C_{N}(€ / \mathrm{kWh})$ : the charge for the prosumer is calculated using the net energy consumed in a billing period.

- Non-netted $\operatorname{cost} C_{N N}(€ / \mathrm{kWh})$ : the charge is calculated using the total energy consumed by the prosumer, i.e., the sum of the imported energy from the grid and the self-consumed PV energy.

- Grid demand $\operatorname{cost} C_{D}(€ / \mathrm{kWh})$ : the charge is calculated using the total energy imported from the grid.

- Fixed $\operatorname{cost} C_{F}(€$ or $€ / \mathrm{kWp}$ or $€ / \mathrm{kW})$ : this charge may be due to various charge mechanisms that exist, like the standing fees, the power component of transmission and distribution charges, the possible special charge for a NEM prosumer based on the installed power, etc.

Concerning taxes, grid charges or other duties imposed, they can be included in the above categories as well. For example, a full netting policy implies that all taxes and duties are included in the "Netted cost", which means that they are calculated based on the net consumed energy within a netting period. On the other hand, a partial netting policy may imply that part or all of taxes and duties are included in the "Non-netted cost" category, whereas the grid charges may be included in the "Grid demand cost". The latter is influenced by the level of self-consumption, since the higher this rate is, the lower the energy imported from the grid and hence the charge for the prosumer.

In addition, a policy variation may dictate the selling of the excess produced PV energy to the grid at a certain price, similar to the FiT policy. This can be modelled using a revenue element as follows:

- Feed-in repayment $R_{F}(€ / \mathrm{kWh})$ : revenue provided to the prosumer for feeding excess PV energy back to the grid in a billing period.

Obviously, when dealing with certain retail electricity tariffs and NEM policies, a pre-processing is required in order to be able to determine the above cost and revenue elements.

\subsubsection{Calculating Prosumer Profits in a NEM Policy}

Generally, a prosumer that is under a NEM policy may profit either directly from selling excess PV produced energy to the grid, or indirectly through the avoided electricity cost that would have been obliged to pay otherwise. Therefore, in order to calculate the total benefits for a prosumer both types of profits must be evaluated. While the direct profit is straightforward to evaluate, the indirect profit may be more complicated since it contains elements that can be specific to a certain NEM policy. Therefore, before going through the calculation procedure, some important definitions related to such policies are provided.

The Billing Period (BP) is defined as the period when all the relevant elements are calculated and the prosumer is charged. In case the netted energy is positive (i.e., excess of PV energy generated during the billing period), this energy can be either transferred to the next billing period as Renewable Energy Credits (RECS) within a netting period or reimbursed using the Feed-in repayment $R_{F}$. The Netting Period (NP) is a policy setting that determines for how long the RECs are still valid and taken into account for the prosumer charging.

Step 1 For each billing period the following energy-related elements are calculated 
- Total PV generated energy, $E_{G, b p}(\mathrm{kWh}): E_{G, b p}=\sum_{\tau=1}^{b p} E_{G \tau}$

- Total energy absorbed from the grid, $E_{D, b p}(\mathrm{kWh}): E_{D, b p}=\sum_{\tau=1}^{b p} E_{D \tau}$

- Total energy injected to the grid, $E_{F, b p}(\mathrm{kWh}): E_{F, b p}=\sum_{\tau=1}^{b p} E_{F \tau}$

- Total netted energy, $E_{N, b p}(\mathrm{kWh})$, adding any RECs from the previous billing period (if applicable): $E_{N, b p}=\sum_{\tau=1}^{b p} E_{N \tau}+R E C_{b p-1}$

- Total energy consumption, $E_{C, b p}(\mathrm{kWh}): E_{C, b p}=\sum_{\tau=1}^{b p} E_{C \tau}$

Step 2 For each billing period the relative costs and revenues are calculated

- The total cost for the prosumer has a component related to the netted $\operatorname{cost}\left(C_{N}\right)$, a component related to the non-netted cost $\left(C_{N N}\right)$, one related to the grid demand $\operatorname{cost}\left(C_{D}\right)$ and one to the fixed costs $\left(C_{F}\right): C_{N E M, b p}=C_{N} \cdot E_{N, b p}+C_{N N} \cdot E_{C, b p}+C_{D} \cdot E_{D, b p}+C_{F}$

- The total direct revenues for the prosumer (if applicable) for injecting excess PV energy to the grid: $R_{D, b p}=R_{F} \cdot E_{F, b p}$

Step 3 For each billing period the indirect profit due to avoided electricity cost is calculated

- Determine the electricity cost for the prosumer without the PV system based on the existing electricity tariff and the total actual consumption (business as usual scenario). This is denoted as $C_{A, b p}$ and generally can be evaluated as: $C_{A, b p}=\left(C_{N}+C_{N N}+C_{D}\right) \cdot E_{C, b p}+C_{F}{ }^{\prime}$, where $C_{F}{ }^{\prime}$ denotes the fixed cost as before but without any possible charges related to the NEM policy.

- Evaluate the indirect profit in a billing period by subtracting $C_{N E M, b p}$ from $C_{A, b p}$ : $R_{I, b p}=C_{A, b p}-C_{N E T, b p}$

Step 4 For each billing period the total profits, $R_{b p}$, for the prosumer are evaluated

- $\quad$ Adding the direct and indirect profits in the billing period: $R_{b p}=R_{I, b p}+R_{D, b p}$

Step 5 Repeat Steps 1 to 4 for all billing periods within a netting period

- Calculate the total profits in the netting period: $R_{n p}=\sum_{i=b p, 2 b p \ldots}^{n p} R_{i}$

Step 6 Repeat Step 5 for all netting periods within a year

- Calculation of the annual profits: $R_{\text {annual }}=\sum_{i=n p, 2 n p \ldots}^{\text {year }} R_{i}$

\subsection{Third Stage: Financial Analysis and Investment Appraisal}

The calculated annual profits from the Second Stage are used in the financial analysis, where the annual cash flows are utilized. The main financial parameters required for the investment appraisal are the installation/capital costs $(€ / \mathrm{kWp})$, the operation \& maintenance $(\mathrm{O} \& \mathrm{M})$ costs $(\%$ of capital cost), the DR (\%), the investment lifetime (years) and the inflation (\%) of both the electricity prices and the $\mathrm{O} \& \mathrm{M}$ costs. Other financial parameters may be utilized as well, such as the inverter replacement costs at a certain year during the investment's lifetime, the evolution of the feed-in repayment $\left(R_{F}\right)$ for the exported energy to the grid, etc. Also, parameters related to the reduction of PV generation rate at a certain percentage per-year and the change in the consumption profile or the prosumer may be utilized as well. 
The annual calculated cash flows are then used to calculate standard investment appraisal indicators, such as the Internal Rate of Return (IRR), the Simple or Discounted Payback Period (SPP, DPP), the Net Present Value (NPV), etc. The determination of such indicators is important when evaluating an existing or proposed NEM policy, since, for instance, a low IRR or NPV value may indicate that the NET policy will not attract investors, while a high IRR or NPV value may imply that the policy favors prosumers at the expense of the rest electricity consumers.

\section{Definition of the Case Study and Policy Scenarios}

This section presents the case study used to test the methodology detailed in the previous section under different policy scenarios. Utilizing this methodology and focusing on the Greek case, presented in Section 2, several policy scenarios can be investigated regarding variations of the NEM policy. In fact, while there is no general EU policy for NEM to guide member countries towards specific energy policies, it is crucial to examine a series of different cases to fully assess the benefits of NEM for optimizing the usage of the PV capacity. Different cases are formulated in a series of Scenarios that are considered separately, having a life-cycle of 20 years.

\subsection{Policy Scenarios}

The policy Scenarios involve a residential prosumer in the Thessaloniki area, Greece and can be distinguished in two general types, i.e., full netting and partial netting. A further categorization of the Scenarios under study involves the treatment of the excess generated electricity. The aim is to analyze the level of influence of the various techno-economic parameters that determine the operation of a $\mathrm{PV}$ installation. The prosumer is charged with the most common residential tariff ("G1" tariff) of the Public Power Corporation S.A. (Athens, Greece) [27]. An analytical description of the different charges in the "G1" tariff is summarized in Tables $2-4$.

Table 2. Competitive Tariff Charges, Standing Fees and Minimum Charge of G1 Tariff scheme.

\begin{tabular}{|c|c|c|c|c|c|c|c|}
\hline $\begin{array}{l}\text { Limits } \\
(\mathbf{k W h})\end{array}$ & $\begin{array}{c}\text { Competitive } \\
\text { Tariff Charges } \\
(€ / \mathbf{k W h})\end{array}$ & $\begin{array}{l}\text { Standing } \\
\text { Fees } 1 \mathrm{ph} \\
(€ / \text { Period) }\end{array}$ & $\begin{array}{l}\text { Standing } \\
\text { Fees } 3 \mathrm{ph} \\
(€ / \text { Period) }\end{array}$ & $\begin{array}{c}\text { Capacity } 1 \\
\text { ph (kVA) }\end{array}$ & $\begin{array}{c}\text { Capacity } \\
3 \text { ph } \\
\text { (kVA) }\end{array}$ & $\begin{array}{c}\text { Min. } \\
\text { Charge } 1 \\
\text { ph }(€)\end{array}$ & $\begin{array}{c}\text { Min. } \\
\text { Charge } 3 \\
\text { ph (€) }\end{array}$ \\
\hline $\begin{array}{l}0-2000 \\
>2000\end{array}$ & $\begin{array}{c}0.0946 \\
0.10252\end{array}$ & 1.52 & 4.80 & 8 & 25 & 5.30 & 8.58 \\
\hline
\end{tabular}

Table 3. Regulated Tariff Charges and Services of General Interest Charges of G1 Tariff scheme.

\begin{tabular}{|c|c|c|c|c|c|c|}
\hline \multirow[b]{2}{*}{ Limits (kWh) } & \multicolumn{2}{|c|}{ TSO } & \multirow[b]{2}{*}{$\begin{array}{c}\text { Rest Charges } \\
(€ / \mathbf{k W h})\end{array}$} & \multicolumn{2}{|c|}{ DSO } & \multirow{2}{*}{$\begin{array}{c}\text { Services of } \\
\text { General } \\
\text { Interest }(€ / \mathbf{k W h})\end{array}$} \\
\hline & Power Charges & Energy Charges & & $\begin{array}{c}\text { Power Charges } \\
(€ / \text { kVA } \times \text { PF/year })\end{array}$ & $\begin{array}{c}\text { Energy } \\
\text { Changes } \\
(€ / \mathbf{k W h})\end{array}$ & \\
\hline $0-1600$ & \multirow{3}{*}{0.16} & \multirow{3}{*}{0.00563} & \multirow{3}{*}{0.00046} & \multirow{3}{*}{0.56} & \multirow{3}{*}{0.0214} & 0.00699 \\
\hline $1601-2000$ & & & & & & 0.0157 \\
\hline $2001-3000$ & & & & & & 0.03987 \\
\hline
\end{tabular}

Table 4. Excise Duty, Special Duty for RES and VAT.

\begin{tabular}{cc}
\hline Other Charges & \\
\hline Excise duty & $0.0022(€ / \mathrm{kWh})$ \\
Special duty for RES & $0.02487(€ / \mathrm{kWh})$ \\
Special duty $5 \%$ & $0.50 \%$ \\
VAT & $13 \%$ \\
\hline
\end{tabular}

Generally, there are three charge categories, namely the competitive charges, the regulated charges and various dues and taxes. Specifically about the "Services of General Interest" (SGI) charge, it is 
used to compensate the higher electricity production cost in the islands (expensive diesel generators) compared to the mainland Greece (majority from cheap lignite power plants) and to cover the provision for the considerably reduced Social Residential Tariff.

The limits that are shown in the first column of Tables 2 and 3 concern the total consumption of the consumer during the entire billing period (4-months). This means that the charges are dependent on the 4-month consumption and the final charge is not scalable. For instance, if the 4-month consumption is higher than $2000 \mathrm{kWh}$, then all $\mathrm{kWh}$ consumed are charged with the same (higher) price of $0.10252 € / \mathrm{kWh}$. Furthermore, it is assumed that the PV capacity is not limited by space or other barriers.

It is evident by comparing the LCOE calculations in Table 1 and the "G1" Tariff that PV grid parity has already been reached for certain values of DRs. In several cases "production cost" parity has been reached as well, which is a situation encountered when the LCOE is lower than the competitive charges of a certain electricity tariff.

In contrast to the current NEM policy in Greece, where excess electricity can be transferred to the next billing periods (RECs) within a year, the other scenarios examined here use the historical System Marginal Price (SMP) values or the 2015 FiT value $(0.115 € / \mathrm{kWh})$ to compensate the excess electricity. By compensating the excess electricity with the SMP values a policy close to a market-based electricity pricing is simulated. This is justified as the reimbursement of the PV produced energy in the actual energy market would have been made using the SMP values. At all times, the SMP values used here are lower than the current FiT value.

In the following scenarios, different forms of partial netting are examined, allowing for the selection of the tariff element that will be included in the netted, non-netted and grid demand costs. Thus, a detailed assessment of the influence of the different tariff elements (e.g., standing fees, network usage charges, and others) on the prosumer's bill is possible. The scenarios assume an hourly netting period, which means that any excess produced electricity per hour is compensated with either the SMP of the FiT. This approach can form the basis of demand side management strategies from the prosumer perspective, i.e., managing the residence load subject to PV generation margins and market prices conditions. Following, a short description of each Scenario is provided while Table 5 collects their most important characteristics:

- Scenario \#1: Full netting policy with no excess generated electricity transfer. The netting is calculated on an hourly basis and the excess electricity is compensated using SMP historical values and more specifically, the SMP values of 2013. The billing period remains at 4 months, which means that the G1 tariff is used for charging the prosumer. The charge is based solely on the net-energy accumulated at each hour inside the billing period.

- Scenario \#2: Partial netting policy with no excess generated electricity transfer. The netting is calculated on an hourly basis and the excess electricity is compensated using SMP historical values and more specifically, the SMP values of 2013. The tariff applied to the prosumer is similar to Scenario \#1, except that the SGI charge is a non-netted cost element.

- Scenario \#3: Full netting policy with no excess generated electricity transfer. The netting is calculated on an hourly basis and the excess electricity is compensated using the current FiT. The prosumer is charged as in Scenario \#1.

- Scenario \#4: Partial netting policy with no excess generated electricity transfer. The netting is calculated on an hourly basis and the excess electricity is compensated using the current FiT. The prosumer is charged as in Scenario \#2.

- Scenario \#5: This simulates the current NEM policy in Greece, as described in Section 2. The demand cost includes the Transmission System Operator (TSO) and Distribution System Operator (DSO) energy charges, the "rest" charges, the excise duty and the special duty for RES charge. The SGI charge is again a non-netted cost element. 
Table 5. Overview of the main characteristics of the scenarios under study.

\begin{tabular}{cccccc}
\hline Scenario & Netting Period & Excess Energy Treatment & $\begin{array}{c}\text { Type of } \\
\text { NEM }\end{array}$ & $\begin{array}{c}\text { Grid Demand } \\
\text { Cost }\end{array}$ & Non-Netted Cost \\
\hline Scenario \#1 & Hourly & Compensation with SMP & Full & No & No \\
Scenario \#2 & Hourly & Compensation with SMP & Partial & No & Yes (SGI) \\
Scenario \#3 & Hourly & Compensation with FiT & Full & No & No \\
Scenario \#4 & Hourly & Compensation with FiT & Partial & No & Yes (SGI) \\
Scenario \#5 & Yearly & Transfer as RECs & Partial & Yes & Yes (SGI) \\
\hline
\end{tabular}

The scope of the analysis is to assess the attractiveness of a PV system investment under different NEM policies. The flexibility of the methodology (and of the developed optimization tool) allows the consideration of an expanded set of sub-Scenarios utilizing different PV installation capacities, electricity consumption profiles, site characteristics, market price forecasts, economic conditions (i.e., loans) and others.

\subsection{Description of Case Study}

By inspecting the formulated Scenarios it may be realized that the SMP and the consumption profile are the crucial factors that define the prosumer's profits. On the one hand, the volatile SMP affects the revenue from selling energy back to the grid in Scenarios \#1 and \#3, whereas the FiT is constant. On the other hand, the consumption profile determines the level of self-consumption and the hourly netting with certain production profiles, hence affecting all the 5 Scenarios. Consequently, in order for a case study to reach meaningful results, these inputs must be carefully selected. The present study utilizes a simulated consumption profile based on consumption data from a sample of 29 residential consumers located in the Thessaloniki area, Greece. The data refer to the year of 2014. For each consumer, hourly load data is available. We consider the representative prosumer of the sample by averaging the available data of the consumers. Initially, Figures 4 and 5 present the consumption profiles for three periods throughout a year, allowing an easier comparison. Specifically, Figure 4 shows the average daily load diagrams over three periods, of which the 1st period corresponds to the months of April, May, October and November ("period\#1"), the 2nd period to the months of July, June, August and September ("period\#2") and the 3rd to the months of December, January, February and March ("period\#3"). It is evident that the load diagrams do not follow the same pattern. For example, in "period\#3" the consumption is much higher, especially in the late evening hours. This is possibly an indication of electrical heating.

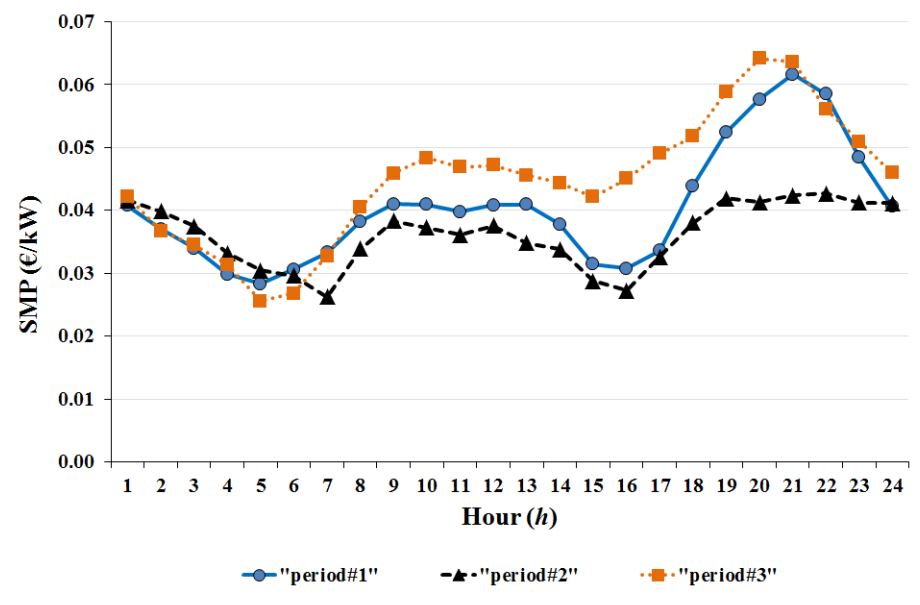

Figure 4. Typical load curves of the different periods. 


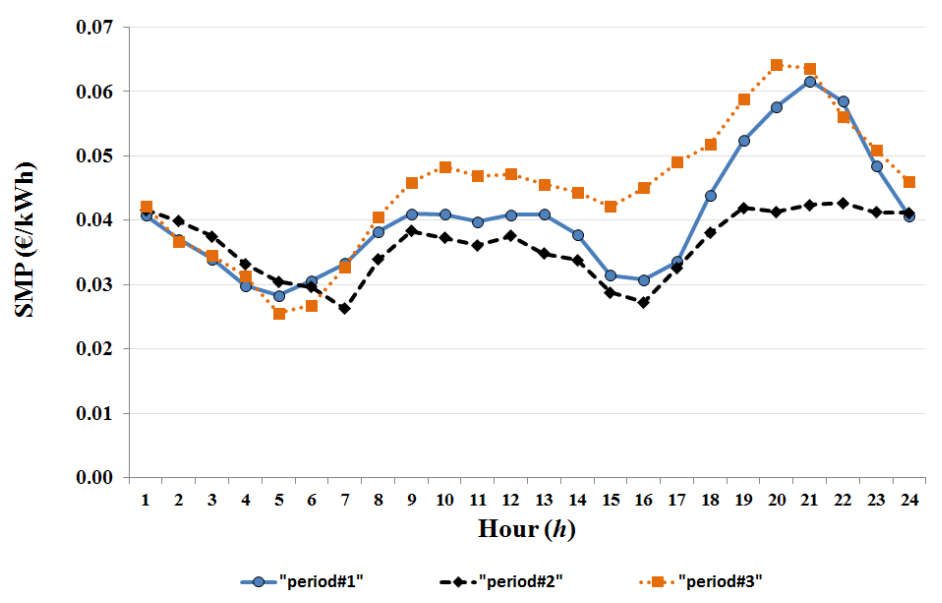

Figure 5. Typical SMP curves of the different periods.

Furthermore, the same periods apply to the SMP values. The Greek wholesale electricity market is structured as a mandatory pool market [28]. The energy and ancillary services are simultaneously traded in a day-ahead market and are dispatched on the available generation units. The objective of the market is to bring efficiencies to short-term system operations and dispatch. For illustrative comparison reasons, average daily SMP diagrams of 2013 are depicted in Figure 5.

Utilizing the methodology of Section 3, the present study considers averaged load curves and system marginal prices separately for weekdays and weekends, for each month. Hence, 24 average load curves are used. Figure 6 illustrates these monthly averaged curves used as input to the case study. With the exception of December, the axis of all other months has the same scaling $(0-0.8 \mathrm{~kW}$ for the left $y$-axis and $0-0.08 € / \mathrm{kWh}$ for the right $y$-axis).

\subsection{Financial Parameters Input}

The financial parameters concerned for the calculations of the case studies are based on actual research concerning the cost of PV systems and relevant literature review [29]. The main financial parameters used here are included in Table 6.

Table 6. Financial Parameters.

\begin{tabular}{cc}
\hline Financial Parameters & \\
\hline Installation cost & $1200-2000 € / \mathrm{kWp}$ \\
Grid connection cost & $390 €$ \\
O \& M costs & $1.5 \%$ of capital cost \\
DR & $5 \%$ \\
Investment lifetime & 20 years \\
Inflation & $2 \%$ \\
Tariff inflation & $2 \%$ \\
\hline
\end{tabular}

The installation cost includes the cost of all required elements of the system (PV panels, inverters, cabling, protection, etc.) and the labor cost. The grid connection cost is the actual cost required by the Greek DSO for three-phase connections (up to $55 \mathrm{kWp}$ of PV power capacity) and includes the inspection and replacement of the existing consumption meter. The Operation and Maintenance (O\&M) costs include the insurance costs of the PV systems as well. This and the electricity prices are assumed to inflate each year with an annual rate of $2 \%$ which is the long-term target of the European Central Bank (ECB). 

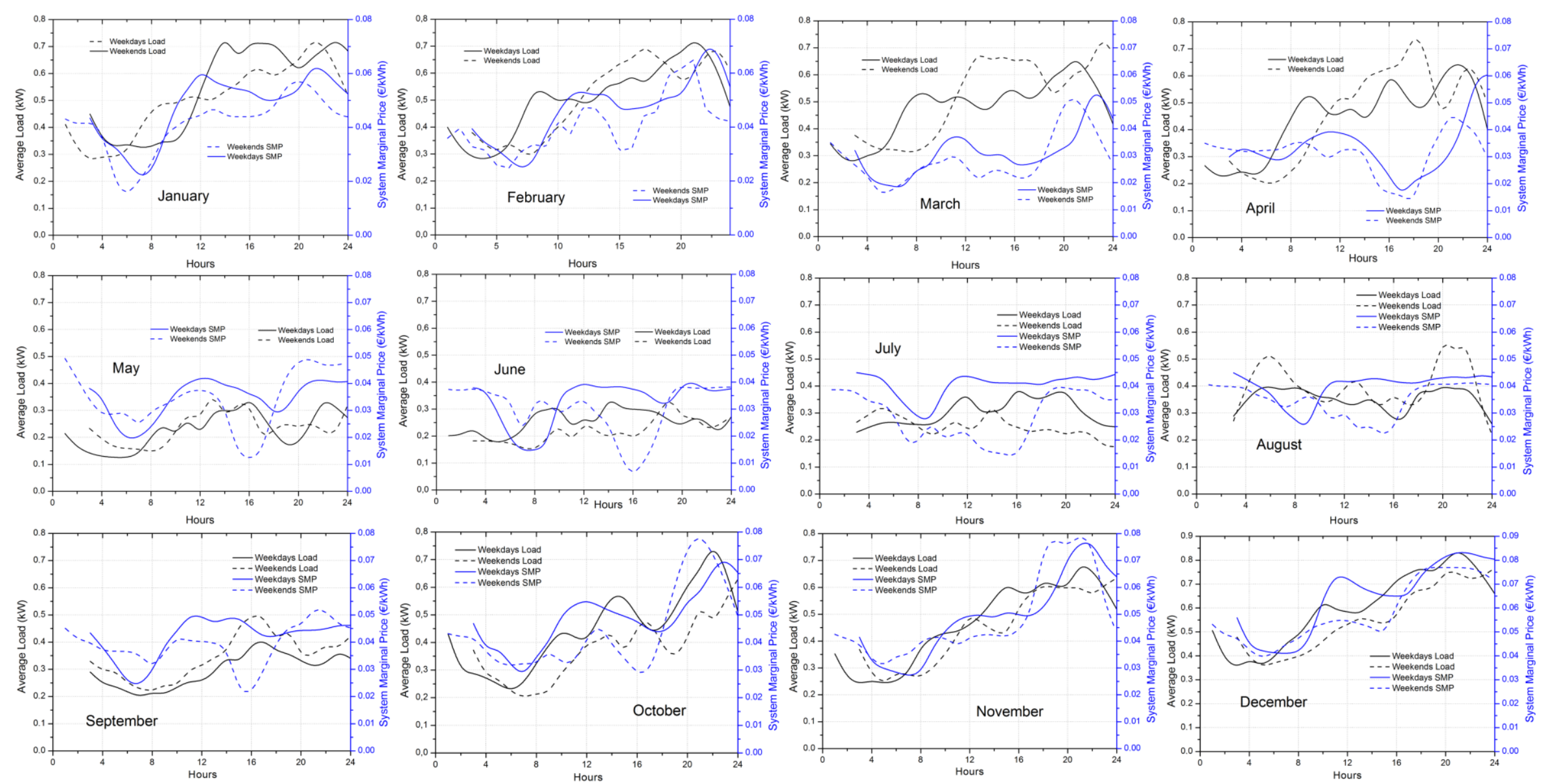

Figure 6. Averaged weekday and weekend load curves and system marginal prices for each month, used in the case study. 
Regarding electricity prices, the competitive tariff charges of Table 2 and the TSO, DSO and the rest charges of Table 3 are allowed to increase at the inflation rate target of $2 \%$ each year. The charges of RES tax and services of general interest are kept constant throughout the 20 year lifetime. This is justified (for the case of RES tax) since the "new deal" that imposed lower FiTs on existing PV installations is expected to minimize the deficit of the electricity market operator and hence, in the worst case, keep the RES tax stable. Regarding the services of general interest charge, taking into consideration that a major part of this charge is due to the high cost of electricity generation in the non-interconnected islands (diesel plants), the announced interconnection of Cyclades islands and Crete will certainly lead to a reduction of this charge or in the worst case keep it unchanged.

\section{Results}

The results section is split into two parts. The goal of the first part is to highlight the influence that certain parameters have on the attractiveness of the current NEM policy in Greece, using a 4-month netting period. The second part of the results aims in investigating the NEM policy scenarios described in Section 4.1. For both cases, the main input is the calculated average consumption for a residential consumer (Figure 6). The prosumer is located in Thessaloniki area in northern Greece and has a contractual capacity of $25 \mathrm{kVA}$ (3-phase connection). The climatic data required to estimate PV production are obtained from the PVGIS platform, while the simple method outlined in Section 3 is used for obtaining the actual PV production, as in [26], with the overall system efficiency being $90 \%$.

Taking as input the average monthly load curves shown in Figure 6 and the respective simulated PV production curves, Table 7 details the monthly consumption, PV generation, and netting, along with the calculated incoming and outgoing energy, for $3 \mathrm{kWp}$ installed PV power. In order to calculate the actual charge for the prosumer under a certain NEM policy, the parameters shown in Table 7 may be required. Then, the profit for the prosumer is determined by subtracting this actual charge from the electricity cost he would have been charged without the PV system.

Table 7. Simulated consumption, PV generation and other parameters of the case study.

\begin{tabular}{ccccccc}
\hline Months & $\begin{array}{c}\text { Consumption } \\
\mathbf{( k W h )}\end{array}$ & $\begin{array}{c}\text { Generation } \\
\mathbf{( k W h )}\end{array}$ & $\begin{array}{c}\text { Netting } \\
\mathbf{( k W h )}\end{array}$ & $\begin{array}{c}\text { Incoming } \\
\text { Energy } \\
\mathbf{( k W h )}\end{array}$ & $\begin{array}{c}\text { Exported } \\
\text { Energy } \\
\mathbf{( k W h )}\end{array}$ & $\begin{array}{c}\text { Self-Consumption } \\
\text { Rate }\end{array}$ \\
\hline January & 382.47 & 204.74 & -177.73 & -241.76 & 64.03 & $68.72 \%$ \\
February & 340.35 & 251.55 & -88.80 & -200.36 & 111.56 & $55.65 \%$ \\
March & 366.71 & 356.57 & -10.14 & -191.79 & 181.64 & $49.06 \%$ \\
April & 321.22 & 403.44 & 82.22 & -143.22 & 225.44 & $44.12 \%$ \\
May & 172.73 & 463.04 & 290.30 & -70.07 & 360.38 & $22.17 \%$ \\
June & 174.45 & 478.40 & 303.94 & -66.88 & 370.82 & $22.49 \%$ \\
July & 209.78 & 506.66 & 296.87 & -84.86 & 381.74 & $24.66 \%$ \\
August & 265.93 & 487.03 & 221.10 & -133.99 & 355.09 & $27.09 \%$ \\
September & 224.63 & 376.83 & 152.20 & -110.28 & 262.48 & $30.34 \%$ \\
October & 319.67 & 301.95 & -17.71 & -183.56 & 165.85 & $45.07 \%$ \\
November & 332.65 & 222.91 & -109.74 & -202.87 & 93.13 & $58.22 \%$ \\
December & 435.96 & 197.64 & -238.32 & -293.23 & 54.91 & $72.22 \%$ \\
\hline
\end{tabular}

\subsection{Assessing the Current NEM Policy in Greece}

As explained in Section 2, the current NEM policy in Greece is a partial-netting policy with a 4-month billing period and an annual netting period. In case excess PV energy is produced within a billing period, the exported energy to the grid is transferred to the next billing period as RECs and not directly compensated. An important parameter that influences the attractiveness of this specific policy is the self-consumption rate, shown in the last column of Table 7. With the current NEM policy in Greece, the higher the self-consumption rate, the lower the energy exported to the grid is and, thus, the demand from the grid is lower as well. This results in increased savings for the prosumer, since 
the regulated tariff charges (apart from the SGI charge) and the special duty for RES are calculated based on the imported energy from the grid. Specifically regarding the case that is shown in Table 7, the annual average self-consumption rate is calculated at $43.32 \%$ approximately. The 4 -month billing periods are assumed to be January-April (with a total consumption of $1410.75 \mathrm{kWh}$ ), May-August (822.9 kWh) and September-December (1312.9 kWh).

As it may be realized by inspecting the "G1" tariff charges of Tables 2-4 and the resulting 4-months averaged consumption, the benefit for this prosumer under the NEM policy is limited. This is because the avoided electricity cost based on actual electricity consumption is calculated with the lower values of the charge elements of Tables $2-4$ (i.e., $0.0946 € / \mathrm{kWh}$ instead $0.10252 € / \mathrm{kWh}$ ). Generally, the "G1" tariff structure favours prosumers that have higher 4-months consumption. Therefore, since high-consuming prosumers are more likely to install a PV system under a NEM policy, simulations are carried out assuming higher consumption as well.

In order to preserve the load curve shapes, the simulated higher consumptions are constructed by increasing the average load curves of Figure 6 by $50 \%, 100 \%$, and $150 \%$. Table 8 collects the average electricity costs for the NEM prosumer under the categories described in Section 3, for the 4 different consumption cases. The average netted and non-netted costs are constructed referring to Tables 2 and 3. For instance, the $50 \%$ higher consumption case considers 4-month consumptions of $2115 \mathrm{kWh}$, $1234 \mathrm{kWh}$, and $1968 \mathrm{kWh}$ respectively, which means that the netted cost $(\mathrm{CN})$ is $0.0946 € / \mathrm{kWh}$ for the $2 \mathrm{nd}$ and $3 \mathrm{rd}$ periods and $0.10252 € / \mathrm{kWh}$ for the 1 st period, resulting in an average netted cost of $0.0974 € / \mathrm{kWh}$.

Table 8. Averaged NEM electricity costs (without VAT) for a prosumer with different consumptions.

\begin{tabular}{cccccc}
\hline Case & $\begin{array}{c}\text { Consumption } \\
\text { Case }\end{array}$ & $\begin{array}{c}\text { Average Netted } \\
\text { Cost } \boldsymbol{C}_{\boldsymbol{N}}(\boldsymbol{\epsilon} / \mathbf{k W h})\end{array}$ & $\begin{array}{c}\text { Average Non-Netted } \\
\text { Cost } \boldsymbol{C}_{N N}(\boldsymbol{\epsilon} / \mathbf{k W h})\end{array}$ & $\begin{array}{c}\text { Demand Cost } \\
\boldsymbol{C}_{\boldsymbol{D}}(\boldsymbol{\epsilon} / \mathbf{k W h})\end{array}$ & Fixed Cost (€) \\
\hline 1 & $\begin{array}{c}\text { Average } \\
\text { Consumption }\end{array}$ & 0.0946 & 0.00699 & 0.05456 & 10.72 \\
2 & $50 \%$ higher & 0.0974 & 0.02085 & 0.05456 & 10.72 \\
3 & $100 \%$ higher & 0.09988 & 0.03181 & 0.05456 & 10.72 \\
4 & $150 \%$ higher & 0.10252 & 0.04321 & 0.05456 & 10.72 \\
\hline
\end{tabular}

It has to be noted that the majority of residential consumers of the sample falls into the first category $(\sim 75 \%)$. The rest is split between the second and third categories (14\% and $11 \%$ respectively). None of the recorded consumptions falls into the fourth case, however, it is studied here since it leads to a higher average netted cost, which may be realized as an indirect FiT.

Utilizing the methodology of Section 3, a series of simulations were performed for each of the 4 consumption cases. The PV installed capacity varies between $1 \mathrm{kWp}$ and $10 \mathrm{kWp}$ while the installation costs vary between $1200 € / \mathrm{kWp}$ and $2000 € / \mathrm{kWp}$ with a step of $200 € / \mathrm{kWp}$. Figure 7 depicts both the calculated IRR and the SPP for each PV-installed power and each installation cost, for the 4 consumption cases. The black rectangles, which are shown on the vertical lines at each installed power value, correspond to a different installation cost, the top being the lowest one $(1200 € / \mathrm{kWp})$.

Inspecting the different graphs of Figure 7, one can conclude that the attractiveness of the current NEM policy is heavily influenced by the installation cost as expected. However, a closer look at the results shows how the attractiveness of the NEM investment increases as the electricity consumption increases. If the IRR is selected as the decisive indicator for choosing the optimum PV power, the value of $2 \mathrm{kWp}$ is the optimal one for the three higher consumption cases. The same result is observed regarding the SPP indicator. The variation of the installation costs between the two extremes results is more than 4 years in the SPP indicator and more than 7\% difference in the IRR indicator (for the $2 \mathrm{kWp}$ optimal power). Moreover, the variation of consumption for the same conditions may lead to differences of more than 1.8 years in the SPP and more than $3 \%$ in the IRR indicator. 

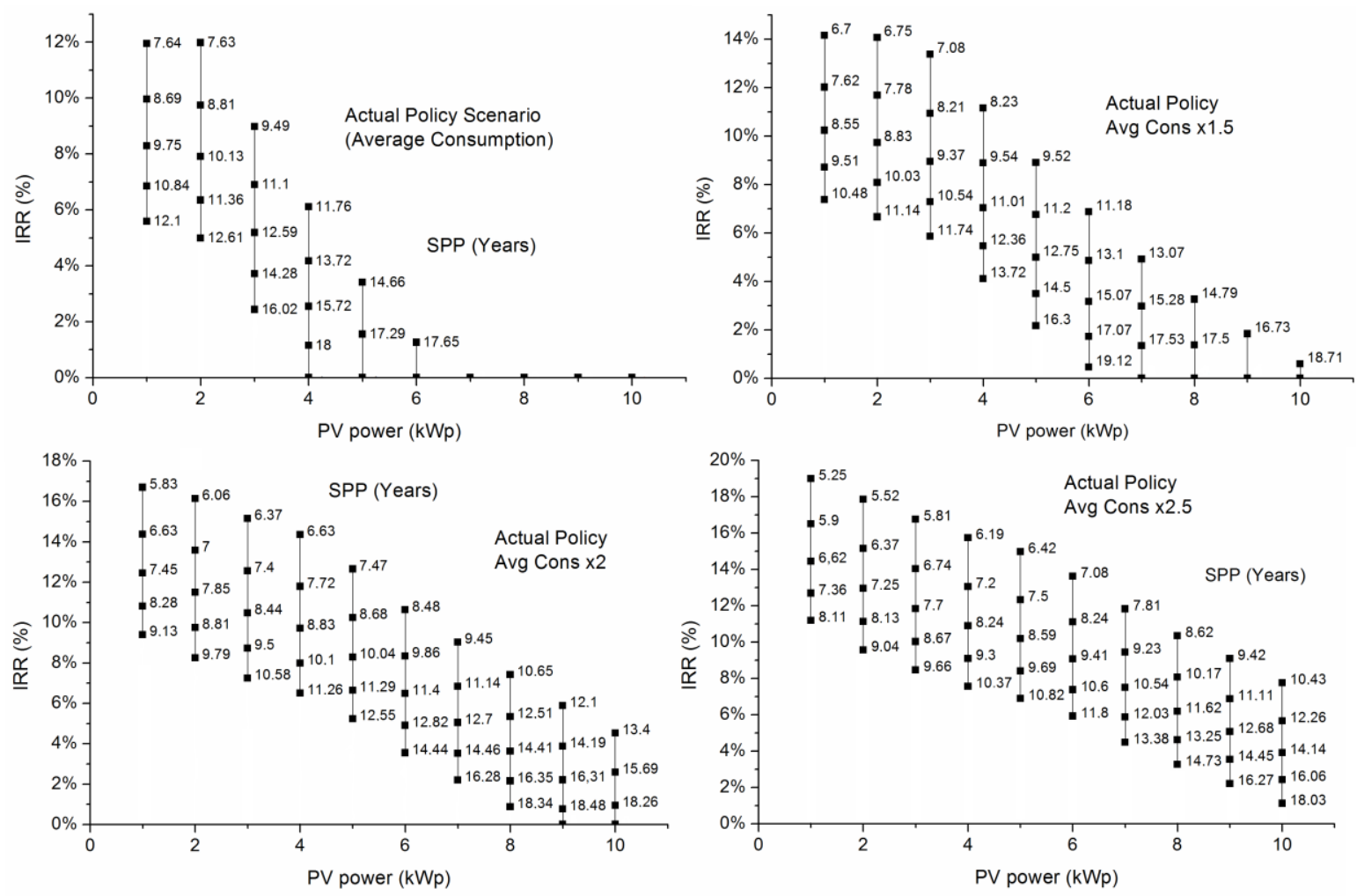

Figure 7. Variation of IRR and Simple Payback Period (in years) for different PV installed capacity and average consumption, under varying installation costs $(1200 € / \mathrm{kWp}$ to $2000 € / \mathrm{kWp}$, with $200 € / \mathrm{kWp}$ step, from top to bottom vertically, at each black rectangular symbol).

\subsection{Investigating Alternative Net-Metering Policies}

The results of the previous sub-section indicate that under certain conditions and capital costs, a NEM investment can become considerably attractive for a prosumer, exceeding in many instances a 10\% IRR. This may imply that the current policy favours NEM prosumers at the expense of other electricity consumers. For example, by allowing a yearly netting period the prosumer can offset the PV energy produced with consumed energy at different times, which presupposes the existence of the grid, an asset that all consumers pay for its services, maintenance, and development. Moreover, this results in reduced revenue for the grid operator and the VAT. These may lead to an increase of retail prices to counterbalance the loss revenues. This can be characterized as a macroeconomic rebound effect. In this case, the prosumer is less influenced with respect to other consumers.

Therefore, policy-makers may have to consider alternative policies, more closely related to market-based ones, in order to form a win-win situation for all parties involved. Such policies may involve a smaller netting period (e.g., hourly netting) in order to influence lower grid interaction, or may forbid the transferring of excess produced energy in the form of RECs and instead allow for selling the energy with the market price of that time step (i.e., the SMP).

The four alternative policy scenarios detailed in Section 4.1 are constructed in this direction, especially since the netting period is reduced to $1 \mathrm{~h}$, instead of 1 year in the current NEM policy. Consequently, the aim of this section is to investigate if such alternative policies compare with the current NEM policy in terms of attractiveness to a prospective investor.

The base case examined here takes as input the average load curves of Figure 6 increased by $100 \%$. The justification for this choice is that it is more likely for a high-consumption prosumer to install a NEM PV system than for a low-consumption one. Initially, the installation cost is set to $1400 € / \mathrm{kWp}$ and the four alternative scenarios are compared with the current NEM policy (Scenario 
\#5) under varied PV-installed power. Figure 8 depicts the variation of the IRR indicator for each of the 5 scenarios considered.

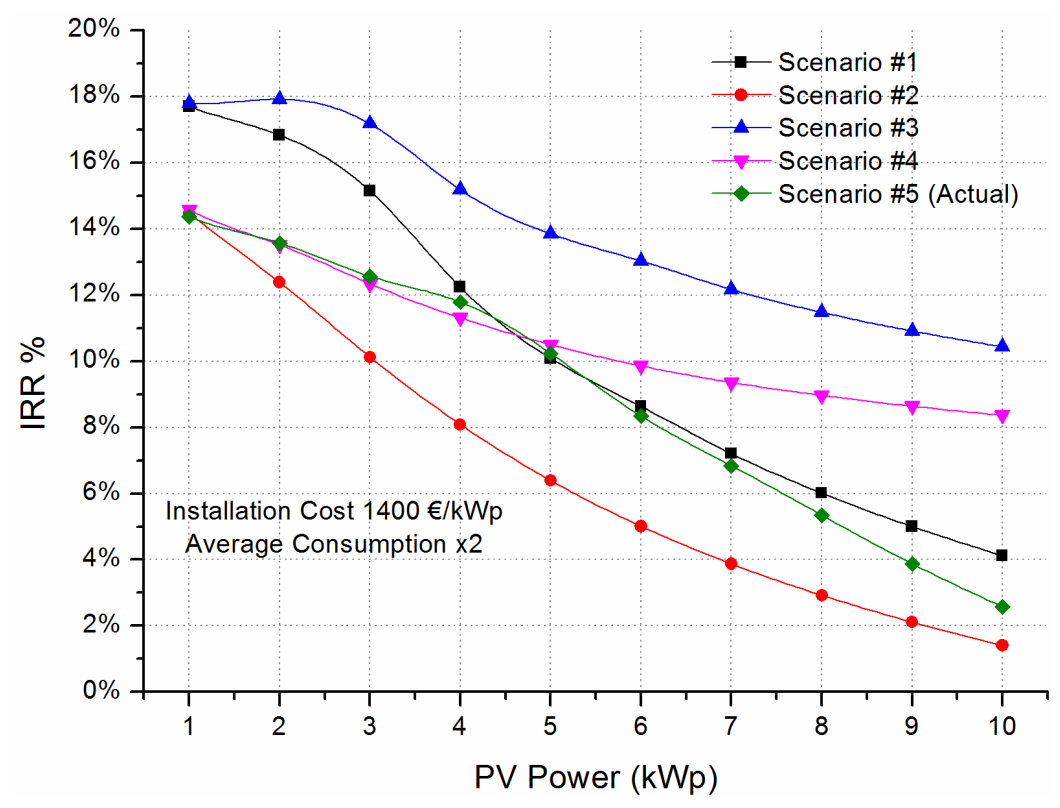

Figure 8. Variation of IRR for different PV installed capacity and 100\% increased average consumption, under 4 alternative NEM policies and the current one.

The results of Figure 8 show that the current NEM policy is generally less favorable to the prosumer than the examined alternatives, with the exception of Scenario \#2. However, the IRR indicator does not measure the absolute size of the investment and, therefore, the same graph is repeated showing the NPV variation in Figure 9. The DR used is 5\%, taking into account the ECB's target inflation of $2 \%$, plus a $3 \%$ investment risk-premium.

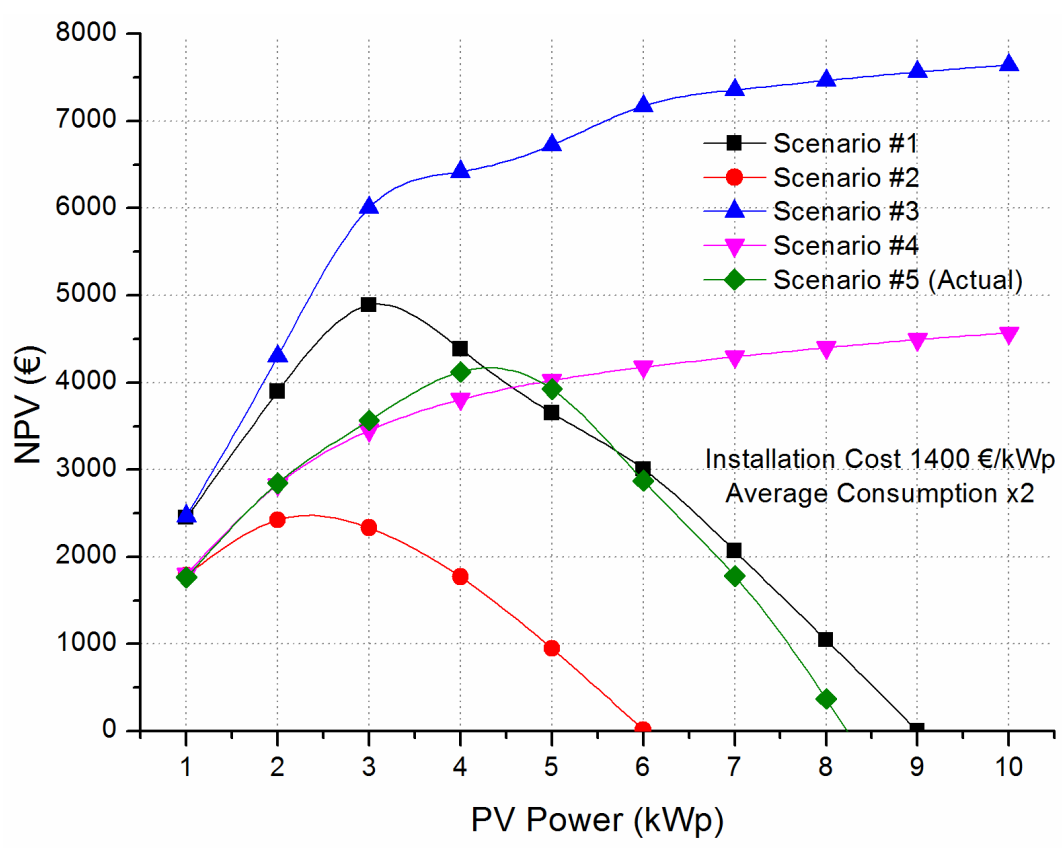

Figure 9. Variation of NPV (with a DR of 5\%) for different PV installed capacity and $100 \%$ increased average consumption, under 4 alternative NEM policies and the current one. 
Comparing the results from the NPV variation in Figure 9 with the ones from the IRR variation, it may be realized that the optimal PV-installed power ranges between $2 \mathrm{kWp}$ (Scenario \#2) and $4 \mathrm{kWp}$ (Scenario \#5-current NEM policy). Also, the compensation of the excess energy with the current FiT that is foreseen in Scenarios \#3 and \#4, leads to an optimal PV power higher than $10 \mathrm{kWp}$.

Since the NPV depends on the DR, the above simulations were repeated for $0 \%$ and $10 \%$ DR values as well. The following Figure 10 illustrates the dependence of NPV on the DR for Scenarios \#1, $\# 2$ and \#5 with varying PV installed capacity.

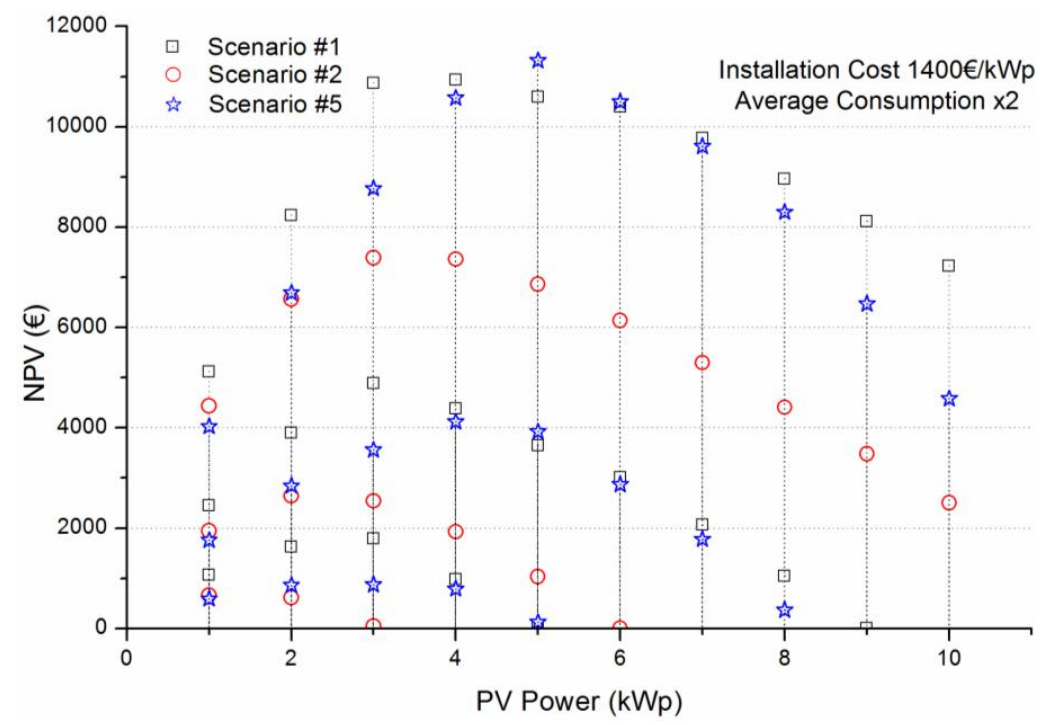

Figure 10. Variation of the NPV for different PV installed capacity under varying DR $(10 \%, 5 \%$ and $0 \%$, from top to bottom vertically, at each symbol).

Next, the influence of the installation cost parameter is examined. Figure 11 shows the variation of the IRR indicator for all scenarios, under varied installation costs with $200 € / \mathrm{kWp}$ step. Furthermore, Figure 12 depicts the variation of the DPP indicator using a DR of 5\%. In both graphs, the installed PV power is $2 \mathrm{kWp}$ and the consumption is taken as double the average profile of Figure 6.

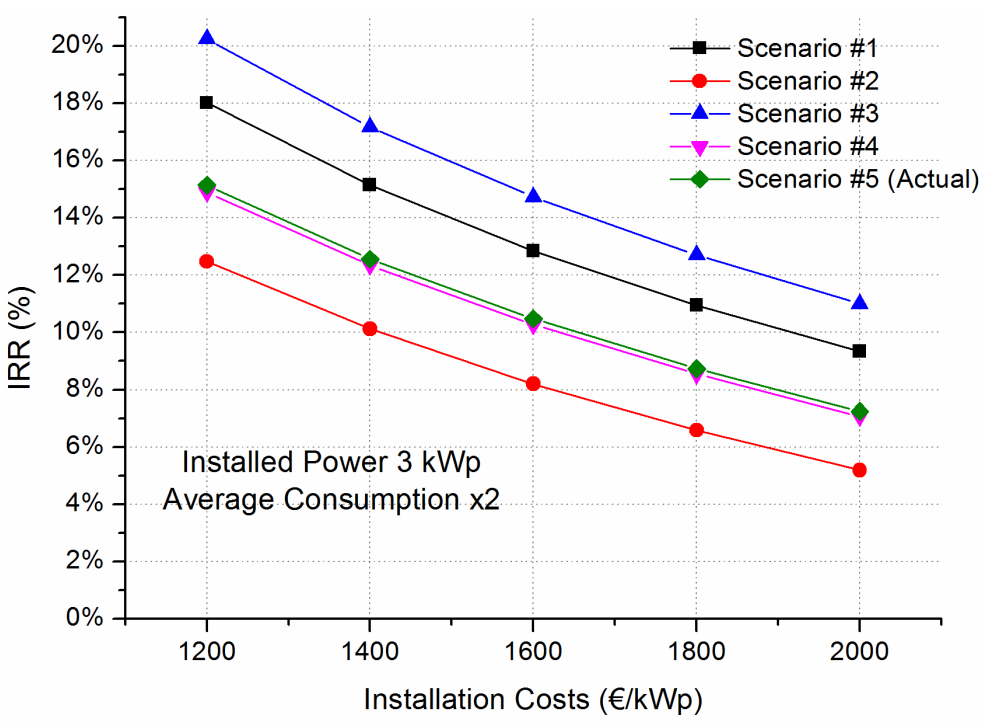

Figure 11. Variation of IRR for different installation costs, $3 \mathrm{kWp}$ PV installed capacity and 100\% increased average consumption, under 4 alternative NEM policies and the current one. 


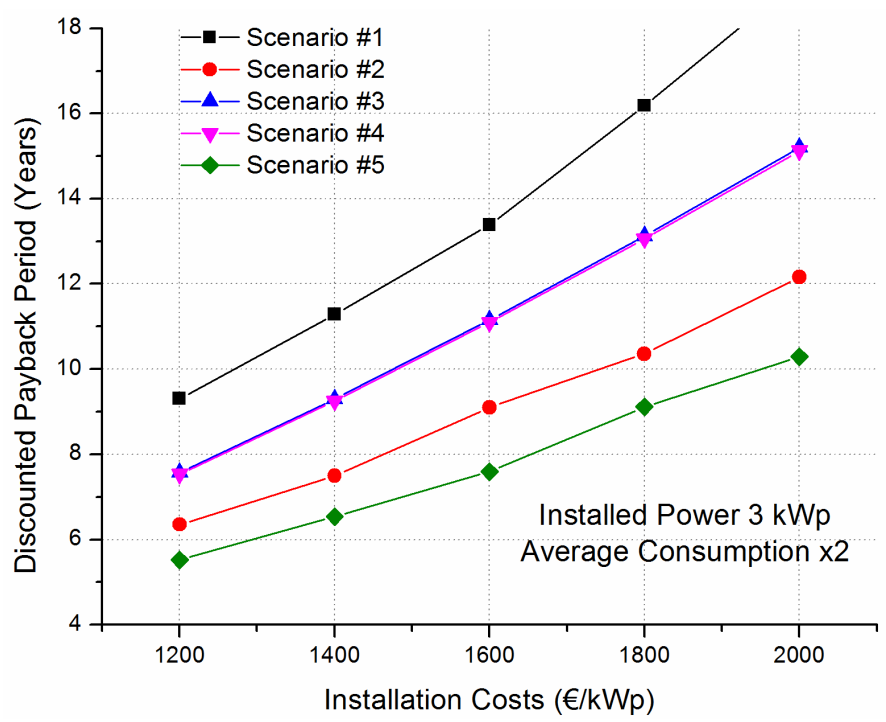

Figure 12. Variation of DPP for different installation costs, $3 \mathrm{kWp}$ PV installed capacity and 100\% increased average consumption, under 4 alternative NEM policies and the current one.

The results shown in both Figures 11 and 12 indicate the heavy influence of the installation cost on the investment's attractiveness. Further on, such graphs may be used to dictate a possible policy adaptation to a less favourable one for the prosumer when installation costs decrease, but at the same time keeping the desired investment return.

Finally, Figure 13 shows the influence of the consumption profiles of the prosumer on the IRR indicator, with PV installed capacity of $2 \mathrm{kWp}$ and installation costs at $1400 € / \mathrm{kWp}$, for each of 5 examined scenarios. As shown in Table 8, the increased consumption leads to higher netted costs resulting from the higher electricity pricing according to the residential tariff "G1". Here the conclusions are as expected, i.e., for all investigated scenarios higher consumption leads to increased investment rate of return. Such graphs may be used by policy makers if the aim is to target a certain prosumer consumption profile when designing a NEM policy.

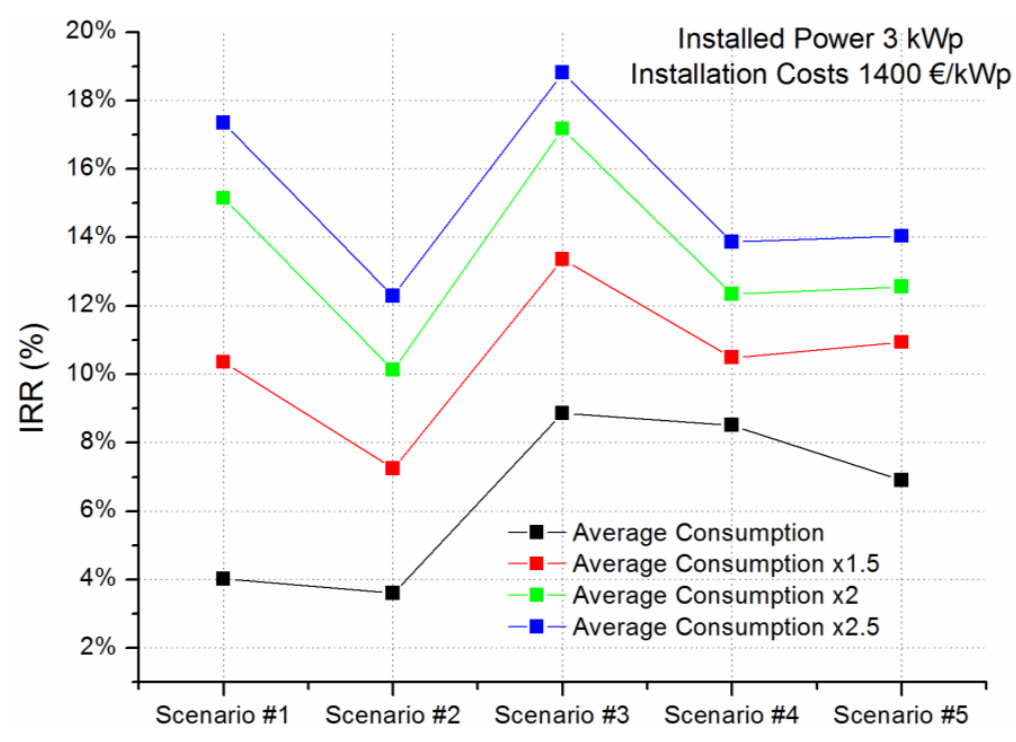

Figure 13. Variation of IRR for different average consumption profiles, $3 \mathrm{kWp}$ PV installed capacity, $1400 € / \mathrm{kWp}$ installation costs, for each of 5 examined scenarios. 


\section{Conclusions and Outlook}

NEM can be a promising solution, especially for countries like Greece that are in the transition period after the end of an attractive FiT scenario and before the competitive involvement of storage. Various net-meeting policies have been proposed and exist worldwide, without any particular one being the norm. The main result of this paper is, therefore, the formulation of a generalized methodology for assessing variable NEM policies in terms of profitability of the prosumer. In this context, the proposed methodology is capable of investigating the influence of all relevant parameters on the attractiveness of a certain NEM policy.

In order to test this methodology, a case study was formulated that refers to a residential prosumer in the area of Thessaloniki in the northern part of Greece. The scope of the analysis was to evaluate the current NEM policy in Greece, but also to examine alternative policies using as a basis the notion of hourly net-metering, which is a policy close to self-consumption.

Concerning the existing NEM policy, the results presented show that such an investment is not necessarily attractive for all situations. Consideration of both the anticipated consumption and PV production is necessary, in order, for example, to decide on the optimal PV capacity. Important parameters that influence the attractiveness of any NEM policy and the optimally installed power are the installation costs and the consumption of the prosumer.

Furthermore, the decreasing trend in PV system costs may eventually make different policies, such as the hourly net-metering, attractive as well. This is justified in this paper under different installation costs and using as inputs on one hand the average consumption data collected from 31 consumers in the Thessaloniki area for a period of 1 year and, on the other hand, the average System Marginal Prices. It is shown that under certain conditions and lower installation costs, even such a policy that is more favored by DSO's can be attractive for investors as well, creating a win-win situation.

Undoubtedly, though, in order for a certain policy to be successful, it needs to create a win-win situation between all interested stakeholders and not just prosumers. In this context, a macroeconomic evaluation of NEM and its implications is a challenging topic for future research. The macroeconomic impacts of NEM are country specific; they affect each economy differently. This is strengthened by the fact that NEM is currently not widespread in most countries. For example, NEM can support the PV industry by creating new markets, products, services, and jobs. A possible counter effect will be the decrease of the economic activity of the fossil fuel industry by limiting the need for fossil fuel power due to the implementation of RES technologies such as NEM. However, the aforementioned negative impact depends mainly on the size and the structure of the energy sector of each country. In the retail side, due to the income decrease of the retailer due to the limited electricity sales, the macroeconomic rebound effect will refer to the increase in the electricity rates. This fact may lead to increased costs from a prosumer perspective. Also, the benefits of NEM for the prosumer depend on demographic characteristics. If the prosumer and other electricity consumers not using the NEM mechanism have the same demographic and economic profile, the prosumer may be benefited by the decreased need for electricity purchase.

Summarizing, the macroeconomic impact assessment is a challenging task and depends on the economy of the country and the structure of the energy sector. In order to assess a macroeconomic impact in this level of decisions, NEM implementation should cover a wide range of consumers. As the number of consumers under NEM legislation increases, the influence of the aforementioned decisions becomes more distinguishable.

Acknowledgments: The authors acknowledge the financial contribution of the European Regional Development Fund through the cross-border programme MED and the scientific contribution of all project partners of the PV-NET Metering project.

Author Contributions: Georgios C. Christoforidis organized the work, conceived the methodology, performed the simulations and wrote most parts of the paper. Ioannis Panapakidis and Theofilos Papadopoulos contributed to writing specific parts of the paper, provided with the required input data after performing certain calculations and assisted in designing the tested scenarios. Grigoris Papagiannis contributed in organizing and editing the 
manuscript. Ioannis Koumparoy, Maria Hatzipanayi and George Georghiou contributed equally in the fine-tuning the methodology, selection of scenarios and editing of the paper.

Conflicts of Interest: The authors declare no conflict of interest.

$\begin{array}{ll}\text { Abbreviations } & \\ \text { PV } & \text { Photovoltaics } \\ \text { FiT } & \text { Feed-in-Tariff } \\ \text { NEM } & \text { Net-Metering } \\ \text { RES } & \text { Renewable Energy Resources } \\ \text { RESSA } & \text { Renewable Energy Resources Special Account } \\ \text { T \& D } & \text { Transmission and Distribution } \\ \text { PVGP } & \text { PV Grid Parity } \\ \text { LCOE } & \text { Levelized Cost of Electricity } \\ \text { DR } & \text { Discount Rate } \\ \text { PVGIS } & \text { Photovoltaic Geographical Information System } \\ \text { REC } & \text { Renewable Energy Credits } \\ \text { NP } & \text { Netting Period } \\ \text { SMP } & \text { System Marginal Price } \\ \text { NPV } & \text { Net Present Value } \\ \text { IRR } & \text { Internal Rate of Return } \\ \text { SPP } & \text { Simple Payback Period } \\ \text { DPP } & \text { Discounted Payback Period } \\ \text { TSO } & \text { Transmission System Operator } \\ \text { DSO } & \text { Distribution System Operator } \\ \text { SGI } & \text { Services of General Interest } \\ \text { ECB } & \text { European Central Bank } \\ \text { O \& M } & \text { Operation and Maintainance } \\ \end{array}$

\section{References}

1. Picciariello, A.; Reneses, J.; Frias, P.; Söder, L. Distributed generation and distribution pricing: Why do we need new tariff design methodologies? Electr. Power Syst. Res. 2015, 119, 370-376. [CrossRef]

2. International Energy Agency-Photovoltaic Power Systems Programme (IEA-PVPS). Snapshot of Global PV Markets 2014, 2015. Available online: http://www.iea-pvps.org/index.php? $\mathrm{id}=92 \&$ eID=dam_frontend_push\&docID=2430 (accessed on 13 January 2016).

3. Photovoltaic Barometer. EurObserv'er, 2015. Available online: http://www.eurobserv-er.org/pdf/ photovoltaic-barometer-2015-en/ (accessed on 13 January 2016).

4. Jäger-Waldau, A. PV Status Report 2014, Available online: https:/ / setis.ec.europa.eu/sites/default/files / reports/PV-status-report-2014.pdf (accessed on 13 January 2016).

5. Yamamoto, Y. Pricing electricity from residential photovoltaic systems: A comparison of feed-in tariffs, net metering, and net purchase and sale. Sol. Energy 2012, 86, 2678-2685. [CrossRef]

6. Poullikkas, A. A comparative assessment of net metering and feed in tariff schemes for residential PV systems. Sustain. Energy Technol. Assess. 2013, 3, 1-8. [CrossRef]

7. Poullikkas, A.; Kourtis, G.; Hadjipaschalis, I. A review of net metering mechanism for electricity renewable energy sources. Int. J. Energy Environ. 2013, 4, 975-1002.

8. Dufo-Lopez, R.; Bernal-Agustín, J.L. A comparative assessment of net metering and net billing policies. Study cases for Spain. Energy 2015, 84, 684-694. [CrossRef]

9. Dusonchet, L.; Telaretti, E. Comparative economic analysis of support policies for solar PV in the most representative EU countries. Renew. Sustain. Energy Rev. 2015, 42, 986-998. [CrossRef]

10. Black, A.J. Financial payback on California residential solar electric systems. Sol. Energy 2004, 77, 381-388. [CrossRef] 
11. Mills, A.; Wiser, R.; Barbose, G.; Golove, W. The impact of retail rate structures on the economics of commercial photovoltaic systems in California. Energy Policy 2008, 36, 3266-3277. [CrossRef]

12. Darghouth, N.R.; Barbose, G.; Wiser, R. The impact of rate design and net metering on the bill savings from distributed PV for residential customers in California. Energy Policy 2011, 39, 5243-5253. [CrossRef]

13. Darghouth, N.R.; Barbose, G.; Wiser, R. Customer-economics of residential photovoltaic systems (Part1): The impact of high renewable energy penetrations on electricity bill savings with net metering. Energy Policy 2014, 67, 290-300. [CrossRef]

14. Satchwell, A.; Mills, A.; Barbose, G. Quantifying the financial impacts of net-metered PV on utilities and rate payers. Energy Policy 2015, 80, 133-144. [CrossRef]

15. Polo, A.L.; Haas, R. An international overview of promotion policies for grid-connected photovoltaic systems. Prog. Photovolt Res. Appl. 2014, 22, 248-273. [CrossRef]

16. Talavera, D.L.; De la Casa, J.; Muñoz-Cerón, E.; Almonacid, G. Grid parity and self-consumption with photovoltaic systems under the present regulatory framework in Spain: The case of the University of Jaén Campus. Renew. Sustain. Energy Rev. 2014, 33, 752-771. [CrossRef]

17. Eid, C.; Guillén, J.R.; Marín, P.F.; Hakvoort, R. The economic effect of electricity net-metering with solar PV: Consequences for network cost recovery, cross subsidies and policy objectives. Energy Policy 2014, 75, 244-254. [CrossRef]

18. Nikolaidis, A.I.; Milidonis, A.; Charalambous, C.A. Impact of fuel-dependent electricity retail charges on the value of net-metered PV applications in vertically integrated systems. Energy Policy 2015, 79, 150-160. [CrossRef]

19. Watts, D.; Valdés, M.F.; Jara, D.; Watson, A. Potential residential PV development in Chile: The effect of Net Metering and Net Billing schemes for grid-connected PV systems. Renew. Sustain. Energy Rev. 2015, 41, 1037-1051. [CrossRef]

20. PV-NET Project. Promotion of PV Energy through Net Metering Optimization. Available online: http:/ / www.pvnetmetering.eu (accessed on 13 January 2016).

21. Arrangements for Renewable Energy Issues. Law 4203, 1 November 2013.

22. Installation of RES Units by Autoproducers with Energy Netting. Ministerial Decree 24461, Issue 3583.31 December 2014.

23. Christoforidis, G.C.; Panapakidis, I.P.; Papadopoulos, T.A.; Chrysochos, A.I.; Papagiannis, G.K.; Koumparou, I.; Georghiou, G.E. Assessing policies for photovoltaic net-metering in Greece. In Proceedings of the 9th Mediterranean Conference on Power Generation, Transmission Distribution and Energy Conversion (MEDPOWER 2014), Athens, Greece, 2-5 November 2014.

24. PV Grid Parity Monitor-Residential Sector, Issue 3, February 2015. Available online: http://www.leonardo-energy.org/photovoltaic-grid-parity-monitor (accessed on 8 March 2016).

25. Vokas, G.A.; Lagogiannis, K.V. PV Energy Production over Greece: Comparison of Predicted and Measured Data of Medium-Scale Photovoltaic Parks. Int. J. Eng. Res. Technol. 2013, 2, 3005-3011.

26. Šúri, M.; Huld, T.A.; Dunlop, E.D.; Ossenbrink, H.A. Potential of solar electricity generation in the European Union member states and candidate countries. Sol. Energy 2007, 81, 1295-1305. [CrossRef]

27. Public Power Corporation S.A., Residential Tariff G1. Available online: http:/ /www.dei.gr (accessed on 13 January 2016).

28. Andrianesis, P.; Biskas, P.; Liberopoulos, G. An overview of Greece's wholesale electricity market with emphasis on ancillary services. Electr. Power Syst. Res. 2011, 81, 1631-1642. [CrossRef]

29. Ossenbrink, H.; Huld, T.; Jäger Waldau, A.; Taylor, N. JRC Scientific and Policy Reports: Photovoltaic Electricity Cost Maps 2013; Report JRC 91937; European Union: Brussels, Belgium, 2014.

(C) 2016 by the authors; licensee MDPI, Basel, Switzerland. This article is an open access article distributed under the terms and conditions of the Creative Commons by Attribution (CC-BY) license (http://creativecommons.org/licenses/by/4.0/). 